\title{
LAS POSTURAS DE LA DERECHA TRADICIONALISTA Y CONSERVADORA NAVARRA ENTRE 1929 Y 1940 EN RELACIÓN CON LA REINTEGRACIÓN FORAL.
}

\author{
THE POSTURES MAINTAINED BY TRADITIONALIST \\ AND CONSERVATIVE RIGHT-WING PARTIES IN NAVARRE \\ FROM 1929 TO 1940 REGARDING FORAL \\ REINTEGRATIONISM
}

\author{
Fernando Mikelarena Peña \\ Universidad de Zaragoza
}

\begin{abstract}
SUMARIO: I. INTRODUCCIÓN.- II. EL REINTEGRACIONISMO FORAL EN NAVARRA, LA POSIBILIDAD DE CONVERGENCIA ENTRE EL CARLISMO Y EL NACIONALISMO ENTRE 1919 Y 1923 TRAS LA ASAMBLEA DE PAMPLONA DE 30 DE DICIEMBRE DE 1919 Y LA CRÍTICA DE LA DERECHA CONSERVADORA.III. LA REFUTACIÓN DEL REINTEGRACIONISMO POR PARTE DE ELADIO ESPARZA DESDE DIARIO DE NAVARRA ENTRE 1929 Y 1931. 3.1. El vasquismo del primer Eladio Esparza y su progresiva basculación hacia el treintaynueveunismo. 3.2. Eladio Esparza en la época de director de La Voz de Navarra. 3.3. Las colaboraciones de Eladio Esparza en el diario Euzkadi del periodo 1927-1929. 3.4. Eladio Esparza: regreso a Diario de Navarra. El cuestionamiento del treintaynueveunismo en sus artículos hasta abril de 1931.IV. EL REINTEGRACIONISMO DE LOS CARLISTAS EN LA SEGUNDA REPÚBLICA. 4.1. Joaquín Beúnza y la subsunción del reintegracionismo en la vía estatutaria. 4.2. La postura de Justo Garrán.- V. ELADIO ESPARZA Y EL REINTEGRACIONISMO DURANTE LA REPÚBLICA. SU DEBATE CON JOAQUÍN BEÚNZA.- VI. LAS POSTURAS DE OTROS REPRESENTANTES DE LA DERECHA CONSERVADORA NAVARRA.- VII. ELADIO ESPARZA Y LA REINTEGRACIÓN FORAL PARCIAL TRAS EL GOLPE DE ESTADO DE JULIO DE 1936.- VIII. INICIATIVAS REINTEGRACIONISTAS TRAS EL GOLPE DE ESTADO DE JULIO DE 1936.
\end{abstract}

RESUMEN: En este artículo se examinan las posturas de la derecha tradicionalista y conservadora de Navarra entre 1929 y 1940 en relación con la Reintegración Foral. Se analizan aspectos como las limitaciones de la coalición entre 1921 y 1923 de carlistas y nacionalistas en la Alianza Foral; la refutación que el periodista y escritor Eladio Esparza hizo del reintegracionismo entre 1929 y 1931; las características del reintegracionismo tradicionalista durante la República; la polémica entre Eladio Esparza y Joaquín Beúnza por la subsunción del reintegracionismo en la vía estatutaria; las posturas de otros representantes de la derecha conservadora de Navarra; la puesta en práctica desde la Gestora de la Diputación Foral tras el golpe de Estado de julio de 1936 de una versión reduccionista del reintegracionismo, y los efectos de la Comisión para la Reintegración Foral impulsada desde la Junta Central Carlista de Guerra; y diversas tentativas que en los años 1937 y 1939 trataron de conseguir una 
ampliación de facultades para Navarra en el contexto del nuevo Estado franquista.

PALABRAS CLAVE: Fueros, Reintegración Foral, Navarra, Eladio Esparza, Carlismo, Nacionalismo Vasco.

ABSTRACT: This paper examines the positions that traditionalist and conservative right-wing parties from Navarre maintained regarding the foral reinstatement between 1929 and 1940. The author analyses the following aspects. First, the limitations of the Navarrese Foral Alliance coalition that existed between 1921 and 1923. Second, the refutation of the reintegrationalism defended by writer and journalist Eladio Esparza between 1929 and 1931. Third, the characteristics of the traditionalist reintegrationalism during the Spanish Republic. Fourth, the controversy sprung between Eladio Esparza and Joaquin Beúnza due to the subsumption of the reintegrationalism in the statutory procedure. Fifth, the position of other representatives of the conservative parties. Sixth, the execution by the managing body of the Provincial Council of Navarre of a version of reintegrationalism after the coup of 1936. Seven, the effects of the commission promoted by the "Junta Central Carlista de Guerra" to address the foral reintegration. And finally, the various attempts that in 1937 and 1939 and tried to expand the faculties of the Provincial Council of Navarre.

KEY WORDS: Jurisdictions, Foral Reintegration, Navarra, Eladio Esparza, Carlismo, Basque Nationalism.

\section{INTRODUCCIÓN.}

En este artículo se examinan las posturas de la derecha tradicionalista y conservadora de Navarra entre 1929 y 1940 en relación con la Reintegración Foral. En primer lugar, como preámbulo, se analizan las consecuencias en el escenario político navarro del fracaso del movimiento reintegracionista de 19181919 y las limitaciones de la posterior coalición entre 1921 y 1923 de carlistas y nacionalistas en la Alianza Foral. En segundo lugar, se presenta la refutación que el periodista y escritor Eladio Esparza hizo del reintegracionismo entre 1929 y 1931 desde las páginas de Diario de Navarra tras su viraje ideológico que le llevó del nacionalismo vasco al navarrismo foral. Esa refutación, desconocida hasta ahora, precedió varios años a los contenidos de su más conocido Discurso sobre el Fuero de Navarra de 1935 que se erigiria como el cánon de los postulados navarristas foralcatólicos y habría tenido la finalidad de cortocircuitar la hipotética aproximación de carlistas y nacionalistas en relación con el autogobierno navarro desde su común perspectiva reintegracionista en una coyuntura de agotamiento de la Dictadura primorriverista. En tercer lugar, se repasan las características del reintegracionismo tradicionalista durante la República, en la práctica subsumido en la vía estatutaria, algo defendido por Joaquín Beúnza, el mayor experto en temas políticoinstitucionales del carlismo navarro. Precisamente la refutación de esa vía posibilista por parte de Eladio Esparza y la polémica que entabló sobre ello con Beúnza son los aspectos que se contemplan en cuarto lugar. En quinto lugar se relacionan las posturas de otros representantes de la derecha conservadora de Navarra, más partidarios del eventual reconocimiento por la Constitución republicana del marco foral de 1841 y de su posible reforma en positivo. Por último, tras repasar la trascendencia de 
la puesta en práctica desde la Gestora de la Diputación Foral tras el golpe de Estado de julio de 1936 de una versión reduccionista del reintegracionismo por medio de la resurrección o creación ex novo de diversas juntas, en conformidad con los postulados de Esparza, así como de la Comisión para la Reintegración Foral impulsada desde la Junta Central Carlista de Guerra, se consignan diversas tentativas que en los años 1937 y 1939 trataron de conseguir una ampliación de facultades para Navarra en el contexto del nuevo Estado franquista, algo de lo que no había ninguna noticia hasta ahora.

\section{EL REINTEGRACIONISMO FORAL EN NAVARRA, LA POSIBILIDAD DE CONVERGENCIA ENTRE EL CARLISMO Y EL NACIONALISMO ENTRE 1919 Y 1923 TRAS LA ASAMBLEA DE PAMPLONA DE 30 DE DICIEMBRE DE 1919 Y LA CRÍTICA DE LA DERECHA CONSERVADORA.}

Tras el fracaso de la campaña reintegracionista en la Asamblea de Pamplona de 30 de diciembre de 1918, analizada en un artículo anterior ${ }^{1}$, el escenario político navarro durante los meses posteriores se verá agitado por las tensiones internas dentro del tradicionalismo y por la coalición denominada Alianza Foral a partir de 1921 entre carlistas y nacionalistas en la que la Reintegración Foral era uno de sus ejes programáticos.

Aunque entre enero y marzo de 1919 se advierten diversas disensiones y actitudes en el seno del partido tradicionalista, no son fácil ni exclusivamente atribuíbles a la cuestión reintegracionista ya que también se enmarañaron con las provocadas por la escisión mellista y por la ubicación en la misma de Víctor Pradera. Un ejemplo es la entidad Acción Tradicionalista constituída el 1 de enero de 1919 por un "gran número de jaimistas radicales", según El Pueblo Navarro y Diario de Navarra del día siguiente. En el manifiesto de la misma publicado el día 8 por ese último periódico se reivindicaba la unión de las derechas para vencer a la revolución, así como la defensa de la justicia social, y se combinaba en el epígrafe "Fueros y Patria" la reivindicación de "amplia autonomía, aspirando a la derogación de todas las leyes y pactos hoy existentes", con la crítica a "quienes silben a la bandera de España" y la censura por ser "comparsas de los separatistas" a los carlistas que no criticaron ese hecho el día de la Asamblea. De ello se desprende que su reintegracionismo concordaba con la ortodoxia del partido y que no querian ser identificados con el reintegracionismo de los nacionalistas vascos. Por otra parte, a pesar de que el día 6 de enero El Pueblo Navarro señalara que Acción Tradicionalista había surgido por efecto del "mar de fondo producido en el Partido Jaimista" por la intervención de Pradera en la Asamblea, por la misma campaña de El Pensamiento Navarro "y por la resuelta actitud de los jóvenes carlistas, contraria al acatamiento incondicional de las indicaciones" de aquel, no parece que ese sector se correspondiera con aquellos jaimistas que desde dicho periódico habian defendido un reintegracionismo radical e historicista: el 21 de enero Acción Tradicionalista criticaba en una carta, publicada por Diario de Navarra, al grupo que había dinamizado aquella campaña por desconfiar de su "sinceridad autonomista".

Fernando Mikelarena Peña, "El debate sobre la Reintegración Foral y sobre su modo de implementación en Navarra en 1918-1919. La postura historicista de los fueristas radicales del carlismo", Historia Constitucional: Revista Electrónica de Historia Constitucional, 20, 2019, págs. 623-657. 
Por otra parte, dentro de la vorágine desencadenada por las tensiones entre Don Jaime y Vázquez de Mella que originarian que, en su réplica a los Manifiestos del primero, el segundo divulgara en El Debate entre el 19 y el 22 de febrero que se salía del partido, la mayoría de los jaimistas navarros acordarian en asamblea el 12 de marzo (El Pueblo Navarro de 13 y 14) colocarse a favor de su rey. Con todo, en El Pueblo Navarro de 7 de marzo se publicaba un artículo sobre la descomposición del jaimismo en el que se reproducía otro editado en El Correo Español por el conocido carlista pamplonés Mario Aquerreta en el que decía que, en relación a la "activa y tenaz campaña" reintegracionista sostenida "con denuedo" por El Pensamiento Navarro, "con aplauso unánime de todos los carlistas honrados", tanto la Junta Central como la Regional jaimistas habian respondido "poniendo trabas y dificultades sin cuento, y lo que es más aún, desautorizándonos públicamente esa campaña, tachándonos de separatistas; y todo esto en periódicos anticarlistas". También se reproducía un documento surgido de una asamblea del Comité Carlista Pro Autonomía Navarra (formado por Ignacio Baleztena, Gabino Martínez, Francisco Errea, Martín Larrayoz, José Martinez Berasain, Pablo Archanco, Adolfo Goñi, Jesús Etayo y el citado Mario Aquerreta) en el que criticaban abiertamente a Don Jaime por las órdenes despóticas que abusando de poder había dado y que habían provocado el cisma mellista.

Volviendo a Acción Tradicionalista, el 11 de marzo El Pueblo Navarro recogió una carta de "ese grupo de jóvenes intransigentes" que formaban esa corriente en la que llamativamente pedian a Pradera que rectificara el rumor de su salida del partido jaimista, algo que no surtió efecto pues al día siguiente aquel dimitía de su cargo de diputado a Cortes por Pamplona porque, según declaró ese día a Diario de Navarra no admitía "disposiciones cesaristas" como la de don Jaime y porque no aceptaba "que una región trate de convertirse en cantón" ni "caer en la estridencia nacionalista". De forma llamativa, Acción Tradicionalista, en carta publicada el 16 de marzo en Diario de Navarra, lamentaba la decisión de Pradera de dimitir subrayando su "buena fe" y "criterio independiente y desinteresado" y agradeciendo su trabajo. A partir de ese día no hay más rastros en la prensa de la existencia de ese grupo que no parece que rompiera nunca con el partido jaimista a pesar de que, según Diario de Navarra de 18 de febrero de 1919, acudiera a la asamblea de comisionados para estudiar el régimen foral como un partido más a través de su presidente Martin Echarren y su segundo Esain.

Sea como sea, ni un colectivo ni el otro saldrian de la disciplina del partido, posicionándose a favor de su monarca, frente a Vázquez de Mella y a Pradera, al igual que la mayor parte de los jaimistas navarros.

Asimismo, en el contexto de la campaña electoral de diputados a Cortes de junio de 1919, Víctor Pradera y Joaquín Beúnza, las dos principales personalidades tradicionalistas que habian participado de la solución acordada por la Asamblea del día 30 de diciembre argumentando contra las posiciones reintegracionistas defendidas por los nacionalistas Aranzadi y Cunchillos, polemizaron duramente en la prensa. El 28 de mayo el primero de ellos alegaba en Diario de Navarra que su propuesta en la Asamblea llevaba también las formas de Beúnza y que, por tanto, si él era centralista, también lo era este último. Al mismo tiempo, Pradera acusaba a los jaimistas reintegracionistas señalando que su "antiguo partido se intoxicó de un nacionalismo que no tenía siquiera la virtud de la franqueza". No obstante, impulsado como candidato, según Diario de 
Navarra del 18 de mayo, por elementos tradicionalistas disidentes bajo el nombre de Junta Tradicionalista de Navarra, Pradera saldría derrotado en el distrito pamplonés, quedando por detrás del maurista Celedonio Leyún, del jaimista Joaquin Baleztena y del nacionalista Manuel de Aranzadi.

Dos años más tarde, el reintegracionismo carlista y el nacionalista volverian a converger mediante la conformación de una coalición entre ambos partidos para las elecciones provinciales, la denominada Alianza Foral, cuyo manifiesto constitutivo se publicó en El Pensamiento Navarro el 4 de junio de 1921. De los cinco puntos de su programa, el segundo hacía referencia a la "Reintegración Foral plena y, en ese sentido restauración, como punto de partida, en todo su vigor y eficiencia iniciales, del pacto de 1841, para llegar a la derogación de la nefasta y tiránica ley de 25 de Octubre de 1839, que aniquiló la soberanía de Navarra y de todo el País Vasco, así de cuantas atentaron contra la constitución foral de nuestro País; volviendo al estado de derecho existente en los tiempos en que los pactos de unión con España eran respetados". Los demás puntos tenían que ver con la realización de una política asentada en el catolicismo, con el estrechamiento de lazos con las provincias vascongadas y con el fomento de la lengua vasca, y con medidas de fomento de la economía y de cohesión social².

No hay que olvidar que el reintegracionismo foral en Navarra o treintaynueveunismo (entendido como la doctrina que proponía el regreso al estatus politicoinstitucional previo a la ley de 25 de octubre de 1839) era una reivindicación tanto del tradicionalismo como del nacionalismo vasco en Navarra, tal y como se puede comprobar con la lectura del diario de aquel (El Pensamiento Navarro) y del semanario de este último, Napartarra, durante aquellos años.

La derecha conservadora, fiel al marco de la Ley de Modificación de Fueros de 1841 y que encontraba su altavoz en Diario de Navarra, siempre trató de abrir una brecha entre carlistas y nacionalistas al hilo de subrayar las diferencias de su reintegracionismo, españolista en el caso de los primeros y visto como instrumental como primer paso para la ruptura con el Estado en el caso de los segundos. Ya durante la campaña reintegracionista que desembocaría en la asamblea de 30 de diciembre de 1918 Diario de Navarra efectuaría continuos llamamientos a los tradicionalistas contra la proximidad del peligro bolchevique y sobre la eventualidad de que las reivindicaciones autonomistas fueran un instrumento de los separatistas y actuaran como elemento facilitador de la revolución en el contexto crítico en el que entonces estaba desenvolviéndose España.

En relación con la mencionada Alianza Foral Diario de Navarra criticará severamente dicha coalición durante todo el tiempo que duró la misma. Así el 16 de septiembre de 1922 comentó que el "enigma para muchos" de haber "podido confundirse en el abrazo fraterno los, en tiempos, irreconciliables enemigos" se explicaba por los efectos de la escisión mellista y por la estrategia de los jaimistas navarros "para impedir su ruina y desaparición", existiendo no obstante entre "las masas" carlistas "un movimiento de repulsa" hacia ella. La opinión de dicho periódico recordaba a la critica lanzada por Pradera en contra de los "jaimistas

2 Elena Floristán Imízcoz y Maria Luisa Garde Etayo, "El manifiesto constitutivo de la Alianza Foral (1921)", Príncipe de Viana, Anejo 10, 1988, pp. 147-154. 
nacionalizantes" en su discurso pronunciado por en el acto de inauguración oficial del Centro Católico Español de Pamplona el día 6 de Enero de 19213.

En el contexto del periodo 1921-1923 esa alianza no generó ninguna iniciativa reintegracionista a causa de la dificultad de volver a incluir ese tema en la agenda política por las dificultades que atravesó España aquellos años. Electoralmente, dicha coalición consiguió un éxito relativo en las elecciones de 1921-1923: si bien arrasó en las elecciones municipales en Pamplona de 1922, tuvieron que conformarse con dos diputados a Cortes en 1923 (el jaimista Joaquín Baleztena y el nacionalista Manuel de Aranzadi, ambos por el distrito de Pamplona), fracasando en el de Estella. Aunque lograron dos diputados en las elecciones forales de 1921 (el carlista Ignacio Baleztena por el artículo 29 por Pamplona y el nacionalista Irujo por Estella), en las elecciones forales parciales de 1923 perdieron en Aoiz y solo sacaron uno de los dos que se disputaban en Estella (Irujo), quedando fuera el jaimista Francisco Errea, el otro candidato de la coalición ${ }^{4}$. Los resultados de estas últimas elecciones hirieron de muerte a la misma, que ya se extinguiría. Errea protestó el 15 de junio de 1923 contra Irujo atribuyéndole compra de votos, coacciones, etc. y Diario de Navarra acompañó a la noticia un artículo de opinión sobre el "fracaso carlo-nacionalista" que significaba "una protesta seria contra esa coalición jaimista-napartarra" ya que "los navarros que son hoy, navarros y españoles, no son, ni quieren parecerlo, navarros-vizcaitarras", señalando así la importancia del rechazo de las bases carlistas a compartir escenario con el nacionalismo al interpretar la finalidad separatista del ideario ideológico de este. En el mismo periódico, el 16 de septiembre de 1923, Tomás Arteaga, Secretario de la Junta de Merindad de Estella, se manifestaba en contra de la coalición y decía que en junio los jaimistas de Tierra Estella habían pedido la disolución de la misma cuyo mantenimiento era defendido desde Pamplona y desde El Pensamiento Navarro.

\section{LA REFUTACIÓN DEL REINTEGRACIONISMO POR PARTE DE ELADIO ESPARZA DESDE DIARIO DE NAVARRA ENTRE 1929 Y 1931.}

Como veremos, entre 1929 y 1931 las tesis reintegracionistas fueron refutadas desde las páginas de Diario de Navarra por Eladio Esparza, columnista y novelista que regresó a dicho periódico, después de haber colaborado con él entre 1910 y 1923, siendo su subdirector a partir de 1930 hasta los años cincuenta. La actitud antirreintegracionista de Esparza, al que nadie acompañó y que sufrió los embates de la prensa nacionalista y de la prensa carlista, supuso una mutación radical de su ideario pues hemos encontrado que en los años diez se manifestó públicamente como vasquista y treintaynueveunista, al igual que entre 1923 y 1925 cuando fue director del diario nacionalista pamplonés La Voz

\footnotetext{
Víctor Pradera, Por Navarra, para España : discurso pronunciado por el ex-diputado a Cortes por Pamplona Don Victor Pradera en el acto de inauguración oficial del Centro Católico Español de dicha capital, el día 6 de Enero de 1921, San Sebastián : Graphos, 1921, p. 5.

4 Ángel Garcia-Sanz Marcotegui, Las elecciones municipales de Pamplona en la Restauración (1891-1923), Pamplona, Gobierno de Navarra, 1990; Ángel García-Sanz Marcotegui, Caciques y politicos forales. Las elecciones a la Diputación de Navarra (1877-1923), Pamplona, E1 Autor, 1992; María Cruz Mina Apat, "Elecciones y partidos politicos en Navarra, 1881-1923", en José Luis Garcia Delgado (ed.), La España de la Restauración. Política, economía, legislación y cultura, Madrid, Siglo XXI, 1985, pp. 111-129.
} 
de Navarra. Además, entre 1927 y 1929 colaboró asiduamente con columnas en primera página en el diario nacionalista de Bilbao Euzkadi. Por otra parte, las tesis antirreintegracionistas de Esparza de 1929-1931 alimentarian, según se verá más adelante, su opúsculo Discurso sobre el Fuero de Navarra de 1935 y serian formuladas asimismo en 1935-1936 en el largo e intenso debate que, como veremos, mantuvo con el carlista Joaquín Beúnza, el principal adalid del treintaynueveunismo, rechazando la defensa que hacía este de la subsunción de la vía reintegracionista, imposible de ser desarrollada legalmente, en los cauces del estatutismo conforme al orden constitucional republicano. Antes, Eladio Esparza se había constituído en el principal adversario desde sus columnas diarias del estatutismo republicano y del estatuto común con Vascongadas entre 1931 y 1932, algo que ya analizamos en un artículo anterior ${ }^{5}$. Por lo tanto, Esparza incidió contra el estatutismo y el reintegracionismo con el fin de obstaculizar cualquier entendimiento entre carlistas y nacionalistas, así como cualquier peligro que pudiera derivar de su acción concertada para el estatus de Navarra conforme a la Ley de 1841.

\subsection{El vasquismo del primer Eladio Esparza y su progresiva basculación hacia el treintaynueveunismo.}

Nacido en Lesaka, en la Navarra vascoparlante, en $1888^{6}$, su padre fue secretario municipal de la localidad desde 1878 a 1917. Después de estudiar en el Seminario Conciliar de San Miguel de Pamplona entre el curso 1901-1902 y el curso 1909-1910 con notas muy brillantes ${ }^{7}$, en 1909 decidió abandonarlo ${ }^{8}$, colaborando de forma estable en Diario de Navarra a lo largo de 1910 con el seudónimo de Javier de Miranda ${ }^{9}$ con una serie de artículos, la mayoría de naturaleza literaria. En enero de 1911 pasaria a trabajar como redactor en $E l$ Pensamiento Navarro, donde con el seudónimo de Ramuncho10 publicó con regularidad durante algunos meses artículos literarios y sin mucha sustancia. Aquel mismo año de 1911 regresó a su pueblo natal, donde contrajo matrimonio con la maestra de la localidad Ramona Viela y desde donde retomaría sus colaboraciones con Diario de Navarra con el seudónimo antes citado, así como sus labores de novelista y dramaturgo. Hasta que en abril de 1923 se trasladó a Pamplona para hacerse cargo de la dirección del periódico nacionalista La Voz de

$5 \quad$ Fernando Mikelarena Peña, "Navarra: entre el estatuto vasco y un estatuto singular para Navarra", Iura Vasconiae: Revista de Derecho Histórico y Autonómico de Vasconia, 10, 2013, pp. 436-451. En este artículo de sintesis y de reexamen del proceso estatutario en Navarra durante la República pueden verse todas las referencias bibliográficas existentes sobre el tema.

$6 \quad$ Archivo Municipal de Lesaka (AML), Caja 108/5, Padrón de 1905.

7 Archivo Seminario Pamplona (ASP), Libro de prueba de los alumnos del Seminario Conciliar de San Miguel de Pamplona (1902-1923), cursos citados.

8 http://www.enciclopedianavarra.com/?page_id=9232

9 La identificación de ese seudónimo con Eladio Esparza en Napartarra el 11 de octubre de 1913, en un artículo del Padre Fabo publicado en Diario de Navarra el 27 de agosto de 1916 y en otro artículo del mismo periódico de 15 de octubre de 1917. También en un artículo del mismo Esparza de 25 de febrero de 1943 en Diario de Navarra.

10 Ese dato fue publicado en su necrológica en Diario de Navarra el 25 de marzo de 1961. Asimismo, El Correo Español de 23 de enero y de 4 de febrero de 1911 informó de su incorporación a El Pensamiento Navarro. 
Navarra, continuó residiendo en Lesaka. Simultanéo sus quehaceres literarios desde septiembre de 1917 con el cargo de secretario municipal de la localidad, sucediendo en el mismo a su padre ${ }^{11}$, hasta su dimisión del mismo el 23 de mayo de 1921, sin explicitarse los motivos ni en el libro de actas ni en la carta de dimisión ${ }^{12}$

El repaso exhaustivo de sus colaboraciones en la prensa entre 1910 y 1923 hace pensar que en la primera mitad de los años diez Esparza se posicionaba en un vasquismo tibio y poco comprometido. A resultas de un requerimiento que le efectuó el semanario nacionalista Napartarra el 20 de septiembre de 1913 en relación con un artículo suyo publicado dos dias antes en Diario de Navarra en el que ponía en boca de otra persona diversas críticas al nacionalismo vasco, replicó el 5 de octubre de 1913 planteando la conveniencia de un nacionalismo abierto e incluyente que pudiera abarcar a "todos los que han nacido en el mismo suelo y sienten el cariño de la Patria" y criticando las campañas agresivas "repartiendo mandobles, en vez de sembrar esperanzas" del nuevo partido en Navarra. Esa respuesta no fue del agrado del órgano nacionalista que en su número de 11 de octubre de 1913 se refería a Esparza por su nombre, defendiendo la praxis politica del nacionalismo vasco. La insatisfacción de los peneuvistas con Esparza se mostraron bien a las claras una semana después con una durísima crítica a una novela suya.

No obstante, parece que la ofuscación de algunos nacionalistas con Esparza remitió en los años siguientes. El 16 de enero de 1916 en la sección dominical Euzkarazko saila que Diario de Navarra dedicó a colaboraciones en euskera durante aquellos años, el nacionalista José Agerre, coordinador de la misma, que en 1913 era secretario del Centro Vasco y que en 1918 se haría cargo de la dirección de Napartarra ${ }^{13}$, dedicó a Esparza, que había nacido el mismo año que él y con el que coincidió en el Seminario, un artículo laudatorio que suscitó el agradecimiento del aludido. No obstante, en la misma sección una semana después, el 23 de enero, Agerre reconvenía a Esparza sobre sus deudas con su lengua materna apelando a su condición de euskaldún.

En el verano de 1916 Esparza expresaria repetidamente su vasquismo y su fe en el Renacimiento vasco con artículos sobre los bailes vascos (4 de julio) y sobre los contenidos del folleto Pizkundia (3 de septiembre),

Dos años más tarde, Esparza expresará su conformidad con las tesis recogidas por Jesús de Sarriá en su libro Ideología del nacionalismo vasco. E1 16 de junio de 1918 publicará un artículo en Diario de Navarra en defensa del nacionalismo vasco en expansión, si bien llamaba la atención sobre que eran muchos más los vasquistas que apoyaban el Renacimiento vasco que los estrictamente nacionalistas, atribuyendo "el jalón diferencial" y explicativo de esa contradicción a la relación con España. En su opinión, Sarriá abordaba ese problema resueltamente y de forma satisfactoria. Una semana más tarde, el 24 de

11 El nombramiento como secretario interino el 30 de septiembre de 1917 en AML, Libro 24, Libro de actas de Pleno, 1914-1917, ff. 173v-174; El nombramiento como secretario titular el 14 de octubre en Ibid, ff. $175 \mathrm{v}-176$.

12 Ibidem; AML, Caja 82, 14.

13 Jesús P. Chueca, "José Agerre, euskaltzale eta abertzale baten oroimenez", Geronimo de Uztariz, 3, 1989, p. 92. 
junio, Esparza profundizará más en la cuestión. Sarría, que se mostraba rotundamente nacionalista al afirmar que queremos para nuestra patria nacional la soberanía plena integra, acertaba al propugnar la convivencia con una nueva España cuyas características serian, según describía Esparza en otro artículo del día 30, las de un gran Estado Ibérico, asentado en el pleno reconocimiento de cada nacionalidad constituída en Estado, evitándose los conflictos y "el predominio de uno o varios elementos". El nacionalismo de Sarriá sería un nacionalismo "en el que España no se odia, ni se desgarra, ni se pisotea. Es decir, un nacionalismo que no es separatista".

A fin de año Esparza fomentará desde su cargo de secretario municipal de Lesaka el movimiento reintegracionista en la comarca. Tras un acuerdo del ayuntamiento lesakarra sobre la autonomía de los municipios navarros, al que el ayuntamiento del pueblo vecino de Bera añadiría la reivindicación reintegracionista, los ayuntamientos de la comarca invitarian a todos los pueblos del norte de Navarra a una asamblea a celebrar en Lesaka el 15 de diciembre para estudiar esos temas El propio Esparza redactaría la proclama de la convocatoria y en dicha reunión sería él quien se dirigiría a los asistentes con un discurso, publicado integramente en El Pueblo Navarro los dias 17 y 18 de diciembre, en el que explicó el significado de la Reintegración Foral y que concluía afirmando lo perdido en 1939 y los perjuicios del marco derivado de la ley de $1841^{14}$.

Tras el fracaso del movimiento reintegracionista Esparza no publicará ningún artículo más en su plataforma de Diario de Navarra sobre nacionalismo o sobre fueros, pero publicará otros en lo que se trasluce su veta reaccionaria que ya habia expresado varias veces en los años anteriores.

\subsection{Eladio Esparza en la época de director de La Voz de Navarra.}

Eladio Esparza fue designado en la primavera de 1923 primer director de La Voz de Navarra, el periódico fomentado por el nacionalismo vasco y en cuyo accionariado figuraban nombres de destacados nacionalistas ${ }^{15}$. Cobraba 6.000 pesetas anuales, mil pesetas más de las que cobraba Raimundo Garcia, Garcilaso, su homólogo en Diario de Navarra ${ }^{16}$. A la altura de 1923 la tirada de La Voz de Navarra era de 5000 ejemplares, por 8500 de Diario de Navarra, 2300 de El Pueblo Navarro y 2000 de El Pensamiento Navarro ${ }^{17}$.

Eladio Esparza ostentaría tal cargo hasta el 1 de febrero de 1925, fecha en la

14 Jose María Jimeno Jurío, Navarra y Vascongadas (1917-1919). Reivindicaciones autonómicas y Reintegración Foral, Pamplona, Pamiela/Udalbide/Euskara Kultur Elkargoa, 2008, pp. 245-253.

15 Elena Osés Laurmbe, "La Voz de Navarra", un periódico vasquista Sus primeras campañas, 1923-1931”, Principe de Viana, 184, 1988, p. 416.

16 Ibid., p. 417.

17 Carlos Moreda de Lecea, "Don Mateo Múgica Urrestarazu (Antecedentes, pontificado en Pamplona y algunos aspectos de su pontificado en Vitoria)", Excerpta e Dissertationibus in Sacra Theologia, Vol. XXI, n. 7, 1992, p. 573. Los datos proceden del registro sobre la riqueza imponible del Archivo de la Diputación. En 1928 La Voz de Navarra y El Pensamiento Navarro tendrian la misma tirada, mientras que la de Diario de Navarra ascendía a los 10000 ejemplares y la de El Pueblo Navarro bajaba a los 1400 . 
que fue sustituído por el también lesakarra José Lecároz ${ }^{18}$. Algo más de un un año antes, el 29 de diciembre de 1923 había sido detenido junto con el subdirector y cinco redactores, según informaba el periódico el 1 de enero de 1924, y conducido al Gobierno Civil y más tarde a la cárcel de Pamplona donde quedaron a disposición del Juzgado militar por reproducir un telegrama de Le Matin sobre las responsabilidades en Marruecos, siendo liberado dos días después ${ }^{19}$. Finalmente, según informaba Diario de Navarra de 12 de abril de 1924 el proceso contra Esparza fue sobreseído.

En nuestro repaso de los ejemplares que se conservan en las bibliotecas hemos advertido que, tal y como advirtió Osés Larumbe ${ }^{20}$, las posturas del periódico se caracterizaron, desde el punto de vista relacionado con el status politicoinstitucional de Navarra, por su fidelidad al ideario reintegracionista ligado a la derogación de la ley de 25 de octubre de 1839 y a la defensa, como mal menor, del autogobierno ligado al marco de la ley de 16 de agosto de 1841, lo que le llevó a enfrentamientos dialécticos con Diario de Navarra por el apoyo de este a la Dictadura primorriverista en los conflictos forales desatados por esta.

Si bien es preciso tener en cuenta la influencia de la censura a partir de septiembre de 1923, la realidad es que los textos firmados por Eladio Esparza en el periódico del que era director, por lo general en la sección titulada Interpretaciones, se limitaron en su mayoria a ser divagaciones filosóficoliterarias, sin constatarse posicionamientos claros de una hipotética ideología nacionalista del autor.

Solamente hemos encontrado cuatro textos elocuentes del fervor, en aquel momento, de Esparza por la linea oficial reintegracionista del nacionalismo vasco en Navarra, todos sin firma y a guisa de editoriales. En el primero de ellos, publicado el 27 de enero de 1924, apoyaba las tesis de Alcíbar [seudónimo de Rafael Picavea] en El Pueblo Vasco que afirmaba que la acepción primordial de Fuero en Vasconia "significa e implica (...) atributo, prerrogativa, facultad, libertad de regirse o gobernarse por leyes propias, forjadas por el pueblo mismo que está en posesión del Fuero o de los Fueros". En el segundo, publicado el 26 de abril de 1924, se sostiene que "el pacto de 1841 tiene defectos grandísimos, que originan o que, por lo menos, permiten constantes conflictos entre Navarra y el Estado", siendo "insuficiente para que Navarra desenvuelva su propia vida" y no habiendo inconveniente en su revisión, siempre y cuando fuera pactada y beneficiara a Navarra, ya que dicho pacto "no es el Fuero sino accidentalmente, provisionalmente". En un tercer artículo, de 31 de julio de 1924, habría criticado a Diario de Navarra por afirmar que el Directorio respetaba al Fuero y tergiversar así la realidad del Directorio y la realidad del Fuero. En el último, fechado el 14 de diciembre de 1924, concluía: "nuestro progreso solo puede traerlo la restauración foral".

18 Ángel Sáiz-Calderón, Guía de Navarra para 1925-1926. Anuario Administrativo, Agricola, Bancario, Comercial, Corporativo, Electoral, Industrial, Judicial, de Negocios, Autoridades y Servicios Públicos de la Provincia, Pamplona, Ángel Saiz-Calderón Editor, 1926, p. 34.

19 Ibid., p. 5.

20 Osés Larumbe, op. cit., pp. 418 y 426-430. 
Después de la salida de la dirección del periódico en febrero de 1925, Esparza siguió colaborando en él con artículos de índole filosóficoliteraria que no se referian en absoluto a cuestiones politicas o institucionales desde la óptica del nacionalismo y de bastante poco fuste, siempre publicados en la sección Interpretaciones.

\subsection{Las colaboraciones de Eladio Esparza en el diario Euzkadi del periodo 1927-1929.}

En marzo de 1925 Eladio Esparza regresó a la secretaría del ayuntamiento de Lesaka, primero de forma interina ${ }^{21}$, en propiedad dos meses después ${ }^{22}$. .

A partir de marzo de 1925 Eladio Esparza también publicó colaboraciones en el diario nacionalista bilbaíno Euzkadi, primero de forma esporádica, y más habituales a partir de 1927, casi siempre en primera plana y con su firma. Sin embargo, la mayoría fueron de carácter literario, filosófico, religioso o histórico, de escasa enjundia, por lo general, bajo una sección denominada Glosario. No abordó nunca cuestiones políticoinstitucionales. Todo lo más, a veces mostró su vasquismo en apoyo al poeta José de Arregi (17 de enero de 1928) o a Kirikiño (6 de febrero de 1929).

Con todo, en otros artículos mostró su querencia por un vasquismo cultural y espiritual que presagian los contenidos de su novela La Dama del Lebrel Blanco y los derroteros de sus colaboraciones posteriores en Diario de Navarra a partir de la primavera de 1929. El 7 de junio de 1928 reivindicó que en relación con la identidad vasca y con el euskara "el problema, pues, del alma vasca es un caso de conciencia que debe resolverlo cada uno con una sincera y honda lealtad. No es un problema que se soluciona con pasquines, ni con manifiestos, ni con politica" ya que "la lengua no puede ni debe ser patrimonio de grupos, ni de escuelas ni de partidos. Es el patrimonio de todos los vascos, venido a lamentable merma en el siglo pasado por culpa de los vascos". Asimismo, el 13 de abril de 1929, prosiguiendo otro de cuatro días antes, también sobre el Padre Moret, primer cronista del Reino de Navarra en el siglo XVII, se preguntaba por la cuestión navarra en el marco mental nacionalista: "Pero el Padre Moret, al construir el Reino de Navarra, creó un nuevo problema, sin él advertirlo: el problema de Navarra en el pueblo vasco; ¿fijó una categoría dentro de otra o al margen de la otra?".

Esas últimas reflexiones tiene que ver con los contenidos de la novela $\mathrm{La}$ Dama del Lebrel Blanco que Esparza publicó en 1930 en la Editorial Juventud de Barcelona, cuando ya llevaba más de un año como colaborador habitual de Diario de Navarra. Esparza dedicó la novela a su amigo el afamado tenor Isidoro Fagoaga. De hecho, los protagonistas de la novela son dos trasuntos de él y de Fagoaga, Ramón de Agesta y Juan Ignacio de Mendizar, "navarros del país del Bidasoa, vascos de raza y de sentimiento"23. El desencanto hacia el vasquismo político y la necesidad de vivir el sentimiento vasco de forma individual asoma

\footnotetext{
21 AML, Libro 26, Libro de Actas de Pleno, 1923-1931, Ibid., ff. 67-67v.

22 Ibid., f. 68.

23 Eladio Esparza, La Dama del Lebrel Blanco, Barcelona, Editorial Juventud, 1930, p. 25.
} 
varias veces en la narración ${ }^{24}$. En uno de ellos Agesta afirma: "lo esencial es despertar el sentimiento vasco" y "luego, que cada cual haga lo que quiera"25.

\subsection{Eladio Esparza: regreso a Diario de Navarra. E1 cuestionamiento del treintaynueveunismo en sus articulos hasta abril de 1931.}

El 5 de junio de 1929, siendo todavía secretario municipal de Lesaka, comenzó sus colaboraciones con Diario de Navarra bajo una sección titulada con el mismo nombre de Interpretaciones que la que tenía en La Voz de Navarra. Un año después, en julio de 1930, abandonaría su trabajo de secretario para hacerse cargo de la subdirección de aquel periódico ${ }^{26}$.

Aunque no ha recibido la atención que se merece, Esparza fue mucho más importante que el director del periódico, Raimundo García (que utilizó los seudónimos de Garcilaso y de Ameztia) para la vertebración de los marcos mentales e ideológicos de la derecha navarrista. Desde finales de los años veinte y durante las dos décadas posteriores, los textos de sus columnas diarias en Diario de Navarra, publicados bajo diversos epígrafes (Postales, Friso Rojo, Mi gacetilla, y también otros) tocaron todos los temas importantes para la politica y la sociedad navarra hasta convertirse en una referencia de lectura ineludible para el ciudadano de entonces y el historiador de hoy. En la cuestión identitaria y políticoinstitucional terminó de perfilar los ejes del llamado navarrismo foral por medio de su concepto de soberanía foral que, como veremos, representaba el abandono definitivo del treintaynueveunismo y la asunción del cuarentayunismo, todo ello bajo la refutación del nacionalismo vasco y del estatutismo republicano, así como también del reintegracionismo, tal y como demuestra el éxito de sus tesis durante el periodo republicano $y$ en el franquismo e incluso en la Transición. Desde nuestro punto de vista, Eladio Esparza estaba muchísimo más dotado intelectualmente que Raimundo García para pergeñar discursos de conformación sociopolítica y era mucho mejor conocedor de la realidad navarra, globalmente considerada, así como de la audiencia a la que se dirigía. Y supo emitir mensajes desde el periódico del que era subdirector, simultáneamente aceptables y movilizadores, para el mayoritario sector tradicionalista de la opinión pública (y que tenía en el periódico carlista El Pensamiento Navarro su canal propio, pero con un nivel discursivo de menor talla intelectual) y para las élites y las sensibilidades conservadoras del entorno de Unión Navarra, el partido de la derecha conservadora surgido en 1933 e integrado en la CEDA, que constituían el público original de Diario de Navarra.

E1 26 de julio de 1929 publicó el primero de los artículos de esa época en los que cuestionaría el treintaynueveunismo, probablemente con el objetivo de cortocircuitarlo discursivamente ante la hipótesis, plausible a tenor de lo visto en 1918, de que fuera la estrategia con que el nacionalismo vasco quisiera aprovecharse de las demandas de mayor autogobierno para Navarra o para el conjunto vasconavarro en una coyuntura de descomposición de la monarquía y fagocitar al sector más fuerista del carlismo. Tras reconocer que con la ley de 1839, "las Cortes españolas, desde luego, se tomaron unas atribuciones que

\footnotetext{
24 Por ejemplo, en las páginas 69-70, 185, 197, 198 y 253.

25 Ibid. p. 252.

26 AML, Libro 26, Libro de Actas de Pleno, 1923-1931, f. 136v.
} 
nadie se las concedió", a la vez afirmaba: "Pero ¿quién tiene la culpa de que uno se tome atribuciones que no le incumben? El que lo permite". Y colocada la responsabilidad de lo sucedido en el campo navarro, incidía en los problemas que surgirian de eliminar la ley de 1839, preguntándose por la capacidad de los navarros para "asumir la responsabilidad que entraña la gobernación de un pueblo". También preguntaba qué se haría entonces con la ley de 1841, reseñando que la misma fue un contrato verificado entre dos partes, de las cuales una hizo, en obsequio de la unidad constitucional, el sacrificio voluntario de su soberanía.

No volvería sobre el tema hasta ocho meses después. En un artículo del 18 de febrero de 1930 criticaría a los partidarios de la Reintegración Foral preguntando "quién tiene derecho a erigirse en fuerista puro y hacer ver a la opinión que los demás son de linaje bastardo". Un mes después, el 6 de marzo, en un artículo publicado en su nueva sección Postales hablaría de los problemas de regresar al estado que planteaban los treintaynueveunistas.

E1 1 de abril en otra nueva sección titulada Estampas forales criticaría el abandonismo intelectual de los navarros en relación con el Fuero al carecerse de estudios diligentes y totales sobre el mismo y disponerse solamente de "folletos, con reflexiones, más bien sentimentales, sobre los derechos de Navarra". Esparza reivindicaba la necesidad de "un estudio detenido, completo" y denunciaba que "los navarros han estado siempre a ciegas respecto al Fuero y no es justo exigir de ellos actitudes definidas" porque "no es posible amar lo que se desconoce, no es posible defender lo que se ignora". Al día siguiente, el 2 de abril, añadía una reflexión más incisiva: "Con el Fuero se han estimulado, fácilmente, los sentimientos instintivos del alma navarra. $\mathrm{Y}$ el éxito ha sido fácil por la ignorancia supina del Fuero de que ayer hablaba. La ignorancia, cultivada con habilidad, favorece prodigiosamente las precarias floraciones del entusiasmo".

Los dos dias siguientes relativizaba el carácter pernicioso de la ley de 1841 y la misma génesis de la de 1839. El día 3 afirmaba en Estampas Forales sobre la ley de 1841 que "no es juicio acertado el de decir que esa ley abolió los fueros de Navarra y despersonalizó el reino. Podrá ser en todo caso, una parte de la verdad, mas no toda la verdad". Por ello, "lo que conviene e interesa estudiar es el fenómeno espiritual de Navarra que aceptó aquella ley, (...) el pensamiento que entonces prevalecía en Navarra". El día 4 sostenía que la ley de 1839, fundamento de la de 1841, fue producto de la proclama de Espartero y que "la guerra civil no lo fue por luchar navarros contra navarros, en pro de una causa navarra", sino que "Navarra intervino en los dos bandos combatientes en España", siendo el hecho de que "Navarra se consideraba España hasta la exaltación heroica del sacrificio por España".

En respuesta a quienes le acusaban de desorientar y confundir a los lectores en cuestiones forales, algo que comentó el 11 de abril en referencia a críticas publicadas en El Pensamiento Navarro, el 16 lanzaba una reflexión que buscaba abrir una brecha entre carlistas y nacionalistas. Tras mencionar una acepción de Fuero que él mismo había defendido como vimos años antes, la del "derecho inherente a Navarra para regirse y gobernarse a sí misma", se pregunta si "el Fuero consiste en que Navarra sea una nación soberana e independiente" y si "todos los navarros que aman el Fuero" “qquieren que Navarra sea una nación soberana e independiente?”. Tres semanas después, el 8 de mayo, revertía las críticas apuntando que "los antiforales son los que, a todo trance, -ellos sabrán 
por qué- desean el predominio de un concepto foral equivocado, ineficaz y antihistórico; un concepto foral que carece en absoluto de tradición y de autenticidad en Navarra; (...) Un concepto foral, por otra parte, que ellos saben que no es solución definitiva, caso de que pudiera realizarse, sino más bien principio de otra solución, que no es de Navarra ni para Navarra". Al mismo tiempo, a la par que negaba que su actitud sea antivasquista, desafiando a los nacionalistas en vasquismo, prevenía contra la utilización de estos del foralismo, acusándoles de sembrar el confusionismo y de manipular a los tradicionalistas: "Los confusionistas son ellos que en su día quieren hacernos ver que en Navarra se ha perdido el sentimiento foral, y otro nos pintan a Navarra echando lumbre de fuero por todos los poros. Que un dia nos dicen que los carlistas son los héroes de la epopeya foral y otro les endosan la afrenta de haber perdido los fueros".

A lo largo de junio y julio de 1930 prolongará sus reflexiones en otras direcciones. El 4 de junio recalcó que él solamente tenía la aspiración "de que todos los navarros posean un conocimiento claro, definido y auténtico del hecho foral que es nuestra característica privilegiada", lamentando el amor de "conveniencia" al mismo. El 6, también en la sección Estampas Forales, repasa la historia del reino de Navarra, remarcando las alianzas con los reinos de León y de Castilla y la aceptación del idioma castellano y el hecho de que con Sancho el Mayor "se engendra la célula de la Monarquía española", ya que "de él brota la estirpe regia de todos los monarcas españoles" y "su reino es el reino de España". En ese repaso interpreta que "a nuestros reyes auténticos les faltó la conciencia de la nacionalidad navarra, o mejor aún, la conciencia del reino navarro"; "Nuestro mayor rey, aureolado de esplendor imperialista, se llamaba a sí mismo Emperador de España".

El 7 de junio de 1930 lanza sus dardos contra la "reintegración foral, absoluta y plena", consistente en que "Navarra vuelva al ser y estado anteriores a la ley de 25 de octubre de 1839", que "es la norma politica más concretamente acentuada del partido nacionalismo (sic) vasco", admitiendo que él participó de esa opinión "con fervoroso idealismo". A juicio de Esparza, "ninguno de los propugnadores de la reintegración foral, absoluta y plena, desearía retrotraer las cosas para encontrarse en el mismo sitio de su postura con España. Porque aquí el tema obligado de toda esta melodía político-foral es la postura con España. Inútilmente hemos vivido en la creencia de que antaño esa postura era contraria a la de hoy". Añade que, incluso "haciendo caso omiso de esas consideraciones", "el programa político de retrotraer las cosas al ser y estado anteriores a 1839 no es, por lo que a Navarra atañe, factible" por las características de las Cortes navarras. No obstante, acogía también unas palabras de Campión que recomendaba "Contentémonos con el firme propósito de restaurar, en la forma posible, el poder legislativo nabarro".

No sabemos en qué medida los artículos de Esparza atemperaron los impetus reintegracionistas del carlismo. Pero lo cierto es que el 22 de julio de 1930 Diario de Navarra reproducía el manifiesto a los jaimistas publicado por Joaquín Baleztena al ser elegido Jefe Regional en el que, tras hablar de Religión, Patria Española y Monarquía tradicionalista, se refería al ideal de la Reintegración Foral reconociendo que hay que ser "politicos de realidades" y que "la fórmula del todo o nada ya no sirve como sea para acelerar la pérdida del todo". Posteriormente, como veremos, durante el periodo republicano, los 
tradicionalistas mencionarán la reintegración foral como objetivo pero no impulsarán ninguna campaña reintegracionista, propugnando la vía estatutaria como alternativa para alcanzar las facultades perdidas.

Por otra parte, en agosto de 1930 Esparza centrará sus invectivas en los jaimistas más próximos al nacionalismo como una forma de coronar su estrategia. Recordemos que en aquel momento Miguel Esparza Aguinaga (primo por partida doble de Eladio Esparza, originario de Igantzi, al lado de Lesaka, pueblo de donde su padre también habia sido secretario) habia sido obligado a dimitir como director de El Pensamiento Navarro, y que con un grupo de afines había fundado el periódico El Ideal Navarro. Desde este criticaron a las autoridades del partido por lo que sería expulsado del mismo, junto con otras personas como Teodoro Leránoz, presidente del Círculo Jaimista, y Carlos Alzu, presidente de la Juventud Jaimista. Ese periódico se caracterizaba por su fuerismo radical y la defensa del entendimiento entre carlistas y nacionalistas para reeditar la Alianza Foral, tal y como recogía Diario de Navarra el 12 de agosto con informaciones tomadas de El Pueblo Navarro y de La Prensa de San Sebastián. Asimismo, los expulsados fundarian el partido Acción Jaimista con las mismas pretensiones, pero sin tener ningún éxito. De hecho, en septiembre Miguel Esparza pasó a dirigir el periódico nacionalista La Voz de Navarra y tres de los que habian formado Acción Jaimista formaron parte de la candidatura nacionalista a las elecciones municipales del abril de $1931^{27}$. El 10 de agosto Eladio Esparza no se recató en afirmar desde su sección Postales que El Ideal Navarro "intenta dar la puñalada" a El Pensamiento Navarro. En 17 aseveraba sobre aquel periódico que "a las gentes (...) les ha dado por no leerlo ni a título de penitencia" por ser un "semanario de picapedreros", con un título propio de una tienda de camisas y de elaboración "con ingredientes analfabetos".

Meses después, el 6 de febrero de 1931, al hilo de la polémica entre $E l$ Pensamiento Navarro y La Voz de Navarra sobre el significado de la Reintegración Foral, Esparza criticaba la definición que había dado el segundo periódico y que decía que suponía "la restitución a Alava, Guipuzcoa, Navarra y Vizcaya, de su libertad histórica y de la soberanía atemperada por la tradición de la práctica foral, en cuya virtud fijaron ellas mismas su propia constitución, régimen y funcionamiento interno y de relación". En opinión del lesakarra, varias expresiones de la misma ofrecian "pretextos lógicos y abundantes para muchas y diferentes interpretaciones. Y metidos ya en la interpretación holgada que permiten, saltarian las discrepancias copiosamente".

\section{EL REINTEGRACIONISMO DE LOS CARLISTAS EN LA SEGUNDA REPÚBLICA.}

Durante la Segunda República los carlistas mantuvieron una postura ambivalente en relación con la Reintegración Foral. Si bien siguieron con su reivindicación como uno de sus ejes programáticos, en su estrategia de los años 1931 y 1932 apoyaron la vía estatutaria como fórmula que sirviera para recuperar competencias homologables a las que se conseguirían con la fórmula

27 Ángel García-Sanz Marcotegui, Iñaki Iriarte López y Fernando Mikelarena Peña, Historia del navarrismo (1841-1936). Sus relaciones con el vasquismo, Pamplona, Universidad Pública de Navarra, 2002, p. 284. 
reintegracionista. Conocer sus posturas y vaivenes es muy importante porque la Comunión Tradicionalista era la formación politica más importante.

Recién inaugurada el República, el 16 de abril, una primera reunión de representantes del partido carlista de Navarra y de Vascongadas en San Sebastián se zanjó con una nota en la que se decía "nos sumamos incondicionalmente a todos los buenos vascos sin renunciar a estos ideales ni exigir que los demás renuncien a los suyos en defensa de nuestras históricas libertades y de nuestra completa reintegración foral" (El Pensamiento Navarro de 17 de abril de 1931). Asimismo, tras una segunda reunión, celebrada en la misma ciudad el 23, se formuló una declaración más extensa, publicada en $E l$ Pensamiento Navarro el 24, en la que se pedía la derogación de todas las leyes abolitarias de los fueros vasconavarros y el restablecimiento de las antiguas instituciones, amoldándolas "según las necesidades de los tiempos y siempre conforme a la voluntad del pueblo". A ello se añadia: "Razones de hermandad y conveniencia política exigen que en esta reconquista de nuestra personalidad Navarros, Vizcaínos, Alaveses y Guipuzcoanos seamos un único pueblo que reclama su libertad sin que esta unidad de aspiración y de raza implique uniformidad de legislación y de órganos de gobierno sino recabando para cada uno de sus componentes del país Eúskaro lo que sea peculiar de su organización foral".

No obstante, en el proceso estatutario de 1931-1932, durante el primer año, los tradicionalistas apoyarían, como es sabido, el Estatuto denominado de Estella, pactado con los nacionalistas, frente al impulsado por las Comisiones Gestoras de las Diputación en manos republicanosocialistas ${ }^{28}$. De cualquier forma, en la visión jaimista primaba, tal y como se decía en un artículo publicado en El Pensamiento Navarro el 5 de julio de 1931, la reconquista de los "indeclinables derechos", siendo accesoria la cuestión del nombre de Estatuto o Reintegración Foral pues "en este caso, el nombre no hace a la cosa. A ésta, hay que mirar, antes y con más cuidado, que a aquel". Y la finalidad perseguida, según admitía Francisco López Sanz en el mismo periódico el 19 de julio, era instaurar por medio del estatuto que se proponia junto con los nacionalistas un valladar para tener "la facultad de obrar libremente" en materia religiosa. Ese enfoque era repetido por el mismo autor el 28 del mismo mes al afirmar que si se aprueba el Estatuto "podremos respirar tranquilos como católicos" y no si impera la ley general. El mismo punto de vista trasladaría Amadeo Marco en el mismo medio el 8 de agosto.

Tras el fracaso del proyecto de estatuto impulsado por la coalición católicofuerista entre carlistas y nacionalistas por no avenirse con la Constitución en tramitación y romperse aquella por el pacto del PNV con el gobierno en diciembre de 1931 según el cual se sometía al marco constitucional para dar un nuevo impulso a un proyecto estatutario común con arreglo al mismo ${ }^{29}$, la Comunión Tradicionalista se ratificaría el 22 de diciembre de 1931 a favor de la Reintegración Foral, adheriéndose de forma "circunstancial a la idea abstracta de un Estatuto Autonómico que, en tanto no se logre la plena restauración foral, atribuya al País Vasco la mayor posible suma de facultades ordenatorias de sus

28 Fernando Mikelarena, "Navarra: entre el estatuto vasco y un estatuto singular para Navarra", op. cit., pp. 397-401. 
intereses religiosos, morales y materiales". A la par se comunicaba el rechazo de la Constitución por laicista y centralista, así como a la atribución de funciones de redacción estatutaria por parte de las Comisiones Gestoras por no representar al País con las que los carlistas se negaban a colaborar.

En línea con lo anterior, de cara a la primera asamblea del 31 de enero en el que representantes municipales navarros se expresaron por primera vez en relación con este nuevo proceso estatutario, el 27 El Pensamiento Navarro recogía una nota de la Junta Regional Carlista de Navarra que decía que, a pesar de la actitud de no colaboración con las Gestoras en la redacción del proyecto de estatuto, "no siendo, sin embargo, la Comunión Tradicionalista enemiga del Estatuto en abstracto, puesto que quiere para Euskalerria la máxima conquista en materia de reintegración foral, y habiendo sido ya votado por los alcaldes, con el asenso de nuestras autoridades, en agosto último, el proyecto de Estatuto Vasco-Navarro" se estimaba que sus delegados en los ayuntamientos podian "acudir a la Asamblea del día 31 para ratificarse en su voto anterior, favorable al citado Estatuto Vasco-Navarro".

Finalmente, el 25 de mayo de 1932 se reproducía en la prensa una nota de la Junta de la Comunión Tradicionalista del País vasco-navarro en relación con el estatuto en la que se recordaba la nota anterior y se repetía una ambigüedad similar. Por un lado, se afirmaba que el proyecto de estatuto "que en el orden económico significa una notoria regresión en el alcance y amplitudes del Estatuto de Estella, tampoco recoge en el orden espiritual, la fisonomía del País, sino antes por el contrario en su parte dogmática y política, se acomoda al espíritu de la Constitución vigente, que por su laicismo escandaloso y por su centralismo impenitente, tanto pugna con el sentir del pueblo Vascongado". Sin embargo, por otro, aunque se reivindicaba la Reintegración Foral y la derogación de todas las disposiciones contrarias a los fueros desde 1812, con todo, se contemplaban con simpatía los progresos que en varios ámbitos pudieran conseguirse si se aprobaba el estatuto sin cortapisas en las Cortes.

En conformidad con esa ambigüedad, en el seno de la Comunión Tradicionalista se registró una corriente de apoyo al Estatuto común personificada por Joaquín Beúnza que el 28 de mayo de 1932 expresaría en una entrevista a El Día de San Sebastián que "el tradicionalista que vota el Estatuto responde mejor al espíritu del glorioso partido tradicionalista que el que deja de votarlo", lo que fue duramente criticado por Eladio Esparza al día siguiente. En el ángulo contrario Víctor Pradera criticó el 16 de junio en Diario de Navarra a los diputados de Unión Navarra Aizpún y Gortari, pero también a Beúnza, al remarcar el espiritu antiforal y antirreligioso del proyecto de estatuto común.

Aunque la libertad de voto a sus afiliados con cargos en ayuntamientos de cara a la asamblea del 19 de junio en Pamplona acordada a finales de mayo confirmaba la existencia de diversos puntos de vista en la Comunión Tradicionalista, no obstante, el 17 de junio los concejales tradicionalistas del ayuntamiento de Pamplona votaban contra el estatuto común, arrastrando a la institución a esa postura por la ausencia de diversos concejales de izquierda, remarcando los caracteres antiforales del mismo y defendiéndose el regionalismo tradicionalista foralista a favor de la unidad de la España católica. Además, en la misma asamblea del 19, el no de Navarra al estatuto común fue ocasionado primordialmente por el rechazo o la abstención de 111 de los 196 ayuntamientos 
controlados por la derecha, que suponian el 56,5 por ciento de ellos y el 70,2 por ciento del total de los ayuntamientos que no dieron su apoyo a aquél ${ }^{30}$.

Posteriormente el 25 de octubre de 1932, en una nota publicada por la prensa al dia siguiente, los tradicionalistas rechazarian explícitamente el estatuto común y, aunque hablaban de Reintegración Foral y de abolición de la ley de 1839, sugirieron su apuesta por el estatuto navarro como vía posibilista para conseguir "la mayor suma de facultades político administrativas". Esas tesis se recogieron de nuevo en un nota publicada de la Junta Regional Carlista de Navarra publicada en El Pensamiento Navarro el 23 de agosto de 1934 en la que se asegura que el objetivo que se perseguía era "la negociación de un régimen de ampliación de facultades, sobre la base de las que actualmente poseemos, programa de aspiración inmediata y mínima a que mientras las circunstancias no permitan llegar a una plena reintegración foral". Igualmente el 25 de octubre de 1935 un editorial de El Pensamiento Navarro afirmaba que la ley del 16 de agosto de 1841, que para los liberales es su máxima aspiración en materia foral y que si puede tolerarse como punto de partida para sucesivas reivindicaciones forales, no puede admitirse en modo alguno como definitiva, como la suprema aspiración para los que hemos mantenido siempre la protesta viva contra esas leyes producto del centralismo liberal y defendido la plena reintegración foral".

Aparte de todo lo mencionado hasta ahora y de las posturas de Joaquín Beúnza que seguidamente se presentan, en nuestro repaso de todos los números de El Pensamiento Navarro durante esos años no hemos encontrado ninguna propuesta reintegracionista que fuera más allá de las anteriores y que aclarase cómo llevar a cabo su implementación.

Por otra parte, disponemos de algunos indicios sobre el foralismo de las bases del carlismo acudiendo a la revista a.e.t. de la Asociación de Estadiantes Tradicionalistas, revista que publicó una quincena de números en 1934. En el número 1 de 26 de enero de 1934, en segunda página, hay un artículo en defensa del fuerismo del tradicionalismo que lucha "contra dos fuerzas extrañas: De una parte, el separatismo, antiespañol, porque su ideal se reduce descaradamente a la desmembración de la Patria, y antinavarro porque nos encadena a la tiranía cien veces peor de un partido, y al centralismo más absorbente todavía de utópicas fantasías patrioteras. Y de otro lado, el unitarismo de tipo liberal y extranjero, continuación de un siglo de servidumbre, escudada hipócritamente tras el engañoso reclamo de libertades individuales". El artículo defiende "la vieja estructuración hispana", la de "la autonomía foral, no la de unos Estatutos atentatorios a la unidad de la Patria; la autonomia que haciendo grandes a las regiones, transforma esas grandezas en glorias legitimas de España”.

El número 3, de 9 febrero de 1934, de la revista, en cambio, efectuaba una referencia directa al reintegracionismo al afirmar en un artículo sin firma en primera página contra la Comisión Gestora de la Diputación y en defensa de los fueros que "Navarra tiene una aspiración que pudiéramos llamar unánime, aun cuando en su realización existan distintas tendencias: me refiero al problema de la reintegración foral". El texto defendía una nueva corporación foral que sustituyera a la Comisión Gestora y "que en su día sea la que recogiendo las aspiraciones de Navarra, nos encauce hacia la reintegración foral plena”. De 
forma similar, en el número 4, de 16 de febrero de 1934, un artículo de Jaime del Burgo Torres, presidente de la AET, que contenía el manifiesto programático de la entidad sostenía, en relación con la estructura territorial, la defensa de la patria española y de la "España grande" en sentido foral mediante la reconstrucción de los antiguos reinos, lo que significa para Navarra "la devolución de sus Fueros". Un foralismo reintegracionista, por lo tanto, pero sin ningún eco de las polémicas en torno al mismo de aquellos años y sin ninguna especificación sobre su implementación.

\subsection{Joaquín Beúnza y la subsunción del reintegracionismo en la vía estatutaria.}

Dentro del tradicionalismo fue Joaquín Beúnza el principal defensor del reintegracionismo y de su subsunción en la vía estatutaria durante los años republicanos

Nacido en Pamplona en 1872, hijo de familia campesina, estudió Derecho en la Universidad de Salamanca, donde se licenció en 1895. Posteriormente se doctoró en Madrid y amplió estudios en París. Se especializó en Derecho Foral. Adscrito a la ideología carlista, se unió a la Junta Regional del partido en Navarra y fue elegido concejal de Pamplona en 1899 y en 1901. Fue elegido diputado foral por el artículo 29 en octubre de 1909, repitiendo en marzo de 1913, permaneciendo por lo tanto en el cargo desde aquel año hasta 1917. Vasquista convencido, era a la vez acérrimo adversario de los nacionalistas vascos tal y como mostró en un discurso a la Juventud Jaimista de Pamplona de enero de 1915 en el que criticó su odio a España, su hincapié en lo racial, su laxitud en cuestiones religiosas y su mayor consideración hacia Vizcaya que hacia Navarra a pesar de que esta había sido el único territorio vasco soberano e independiente. También subrayó que el amor a la lengua vasca no debía ir en detrimento del castellano. En 1916 dimitió de la Junta Regional jaimista. Apoyó el proceso reintegracionista de 1918-1919 aunque luego firmase la propuesta que lo finiquitaba en la asamblea de 30 de diciembre de 1918 . Fue asesor de numerosos ayuntamientos (entre ellos el de Pamplona), así como del Banco de España, el Consejo Administrativo y la Diputación Foral, que le declaró Hijo Predilecto de Navarra por su participación en el Convenio Económico de 1927. Por esas fechas era presidente de Hidráulica del Urederra y vicepresidente de Azucarera de Madrid y pertenecía a diversos consejos de administración, fundamentalmente de empresas azucareras. En las elecciones a Cortes Constituyentes de 1931 fue diputado de la Coalición Católico-Fuerista y formó parte de la Minoría Vasco-Navarra, en cuyo nombre defendió el derecho del voto a las mujeres ${ }^{31}$.

Después de haber apoyado los diversos proyectos de estatuto común de 1931 y 1932, en su conferencia en un ciclo organizado la primavera de 1935 por el Ateneo Navarro "sobre los problemas de fueros o autonomía de Navarra en los momentos actuales" en el que intervinieron también otra decena de expertos, Beúnza explicó, según El Pensamiento Navarro de 22 de mayo de aquel año, que defendía un programa de reconquista foral que arranque "de la ley del 41 hasta la

31 Ángel García-Sanz Marcotegui, Diccionario Biográfico de los Diputados Forales de Navarra (1840-1931), Pamplona, Gobierno de Navarra, 1996, págs. 358-361. 
reintegración foral completa, realizando en cada momento lo que se pueda" porque "nuestro derecho es el de la reintegración foral completa", "régimen que a nadie dañaba y que era provechoso para nosotros", "y condición básica de este régimen es el de que seamos españoles. El ser navarro y español son cosas que siempre se han compenetrado". Negó ser separatista: "El separatismo es otra cosa: es el odio a España y el querer separarse de España; pero nunca el desear y defender la reintegración foral. Los navarros han sido españoles, pero fueristas de primera categoria". No obstante, aunque defendia la Reintegración Foral completa, planteaba un programa de ampliación de la autonomía que concediera atribuciones a Navarra en enseñanza, legislación civil, justicia, política agraria, legislación social "y otras varias facultades" porque "llegará el momento en que la Constitución se modifique y no sabremos lo que debemos pedir", siendo "necesario, absolutamente necesario que nos preparemos para ver qué es lo que debemos hacer cuando venga la revisión constitucional", estimada para "principios de 1936". Por último, señaló que "Navarra debe preocuparse de lo que se ha de hacer, de su autonomía, llámese Estatuto, carta foral, carta autonómica, como se quiera" y debía estudiarse "la ampliación de autonomía que se ha de solicitar a las Cortes".

Asimismo, el 25 de octubre de ese año el mismo periódico reproducía una carta suya en la que reclamaba pedir a los navarros que exigieran a la Diputación el inicio de una campaña contra la ley abolitoria de 1839. Y el 20 de noviembre de 1935 Beúnza, bajo el seudónimo de Miguel Ramón que utilizará repetidamente durante esos meses y que hemos podido identificar con su persona, tal y como luego se explicará, se hacía eco de la iniciativa alavesa de la Carta Foral, añadiendo que Navarra estaba "en absoluto ausente del problema de la reintegración foral".

El 13 de diciembre Beúnza, bajo el seudónimo citado, en un artículo titulado "La Carta Foral de Navarra", después de advertir "que nuestro derecho estricto consistiría en la simple derogación de la Ley abolitoria de 25 de octubre de 1839" y que "Esa es la verdadera tesis foral de Navarra dentro del más puro españolismo tradicional", invitaba a la Diputación a tomar la iniciativa, coincidiendo con la opinión expresada dos dias antes por Diario de Navarra. Sin embargo, este último periódico comentaba el 14, tras publicar aquel texto de Beúnza, con un estilo que recordaba al de Esparza, que la argumentación era "borrosa e imprecisa" y que "lo de la derogación de la ley del 39 no deja de ser un aspecto negativo de la cuestión". Y añadia: "La Carta Foral o no es nada o ha de rebasar el contenido de la ley del 39 y de la ley del 41 y de cuantas rozaron en su época y posteriormente la doctrina foral. Nada, pues, de tópicos que ya han perdido su tecla sonora".

El 3 de enero de 1936, en un artículo titulado "La Carta Foral de Navarra. Para terminar" Beúnza subrayaba de nuevo la necesidad de derogación de la ley de 1839, sin que ello significara "que habían de resucitar con esa derogación el estado total de la vida y de las instituciones, según se encontraban en el momento de la abolición del régimen foral". Para Beúnza, dicha derogación significaría la recuperación de todas las facultades perdidas y entrañaria modificar "todo lo imperfecto de aquel modo de ser y creando también todo lo nuevo que Navarra estimase conveniente a sus intereses", pactando "con el Gobierno central de la manera de concordar y armonizar nuestro régimen con el propio del estado". 
Las instituciones se hicieron eco de la idea, presumiblemente por el desarrollo de los trabajos parlamentarios desde el mes anterior sobre el Estatuto Vasco y la posible mención de vías de incorporación de Navarra al mismo ${ }^{32}$, y el 26 de mayo de 1936 la prensa informaba del acuerdo del Consejo Foral Administrativo (que había sido restablecido con algunas leves reformas en su composición unos meses antes por la Gestora de la Diputación de derechas surgida tras las elecciones indirectas de enero de 1935, tras haber permanecido inactivo con las Gestoras republicanas anteriores, y que estaba también plenamente controlado por los partidos derechistas ${ }^{33}$ ) sobre la Carta Foral en el que se solicitaba a la Diputación que trasladara a los letrados asesores de aquel (Pedro Uranga, Rafael Aizpún, Lorenzo Oroz y Joaquín Beunza) y a los diputados por Navarra en Cortes el proyecto de Estatuto navarro que había sido elaborado en junio de 1931 por una ponencia en la que estaban representados los distintos partidos políticos, a fin de que emitieran informe manifestando si dicho proyecto satisfacía las aspiraciones forales y autonómicas de Navarra o propusieran las modificaciones oportunas. Evacuado el mismo, la Diputación seguiría los cauces aprobatorios del decreto de 8 de diciembre de 1931 sobre el proceso estatutario vasconavarro pero para un marco exclusivamente navarro. Sin embargo, ese informe nunca se sustanciaria ${ }^{34}$ y la posibilidad del Estatuto singular para Navarra quedaría bloqueada.

\subsection{La postura de Justo Garrán.}

Otro autor en la órbita del tradicionalismo que expresará sus opiniones a favor del reintegracionismo será Justo Garrán Moso en la obra El sistema foral de Navarra de Navarra y Provincias Vascongadas ${ }^{35}$.

Diputado a Cortes en 1923 por el distrito de Tafalla como católico independiente con el apoyo de integristas y jaimistas, durante la Dictadura de Primo de Rivera fue miembro de la Diputación Foral, propuesto por la Unión Patriótica, entre 1928 y 1930 y fue elegido por la misma como representante suyo en la Asamblea Nacional en septiembre de 1928. Entre 1929 y 1931 presidió la Federación Agro-Social e Navarra y a finales de ese último año fue el principal promotor de la Asociación de Propietarios Terratenientes de Navarra. A lo largo de la República se integró informalmente en el tradicionalismo, En septiembre de 1933 fue elegido candidato junto con Victor Pradera para el tribunal de Garantías Constitucionales por el Bloque de Derechas a iniciativa de la Junta Regional Carlista (Diario de Navarra de 2 de dicho mes). El 13 de febrero de 1934 impartió una conferencia en el Círculo Círculo Tradicionalista sobre análisis de la doctrina carlista, reseñada en El Pensamiento Navarro del día siguiente que dijo de él que era un "incansable propagandista de la Causa, tan aplaudido en los numerosos

32 Manuel Ferrer Muñoz, "La cuestión estatutaria en Navarra durante la Segunda República", Príncipe de Viana, 193, 1991, p. 219.

33 Ángel Pascual Bonís, "La actividad de las gestoras de la Diputación Foral (1931-1939) y sus relaciones con el poder central”, Principe de Viana, 187, 1989, pp. 464-465.

34 Manuel Ferrer Muñoz, "La cuestión estatutaria en Navarra durante la Segunda República", op. cit., pp. 218-219.

35 Justo Garrán y Moso, El sistema foral de Navarra y Provincias Vascongadas, Pamplona, Aramburu, 1935. 
actos en que ha tomado parte". Bien visto por el tradicionalismo, el 19 de agosto de 1936 la Junta Central de Guerra Carlista de Navarra lo nombró, como veremos, miembro de la Comisión para la Reintegración Foral ${ }^{36}$.

Sus posiciones estaban de alguna manera en la órbita del foralismo tradicionalista, aunque con particularidades. Ya el 26 de octubre de 1924 publicó un artículo en Diario de Navarra sobre la Unión Patriótica y los fueros de Navarra en el que recogía algo dificilmente creíble: el propósito programático de la sucursal de dicho partido en Navarra no sólo de conservar el régimen foral, sino incluso de mejorarlo en una eventual reforma del mismo reconquistando las facultades perdidas, y planteaba unas hipotéticas Cortes corporativas navarras a las que se denominarian Junta General del Reino. Sobre esa idea fantasiaria en La Avalancha en su número de 8 de junio de 1925. Como es obvio, esas posturas discrepaban fuertemente de los posicionamientos en torno a la foralidad navarra del Directorio y que desataron diversos conflictos sobre el autogobierno navarro, algunos de gran intensidad como los relativos con el Estatuto Municipal o con el Cupo.

Garrán apoyó el Estatuto Vasco-Navarro en sus versiones de Estella o de las Gestoras enmendado para conformar un espacio autónomo católico como único virtud del mismo (Diario de Navarra, 26 de julio de 1931). El mismo 19 de junio de 1932, dia de la Asamblea de representantes municipales en la que se iba a debatir, se posicionó radicalemente en contra del Estatuto vasconavarro alegando su laicismo, su "tufillo separatista" y la ruptura que suponía el sufragio universal para elegir el parlamento autónomo con respecto a las formas electivas corporativas forales de siempre, apoyando de paso el voto contrario al mismo del ayuntamiento de Pamplona arrastrado por la posición de los concejales derechistas.

En su obra El sistema foral de Navarra y Provincias Vascongadas (Pamplona, Aramburu, 1935) subrayó que había muchos que "aspiran a una reintegración foral completa, es decir, no sólo económico-administrativa y escolar, sino también judicial y aún política" $\mathrm{y}$ diferenció el reintegracionismo de carlistas y nacionalistas. Los primeros "defienden los fueros no sólo por ser antiguos y tradicionales, sino por ser buenos, tanto según la recta razón, como según las conveniencias del país". En cambio, los nacionalistas, ofreciendo "un estado de contradicción teórica y práctica, doblemente interesante" y que serían "menos razonables y consecuentes" solamente veían en la foralidad "un elemento histórico" y "como no han reconocido y estimado su bondad intrinseca, cuando se han visto en el campo de la politica activa, han prescindido de todas sus predilecciones de raza y lengua, tradiciones y constumbres, para tolerar en sus programas y estatutos, proposiciones que no sólo se alejan de las tradiciones e intereses del país, sino que son incompatibles con ellas". "Han pasado pues de la escuela historica, a la escuela abstracta, y condescienden y aun se coaligan con la vigente politica republicana, y no suelen protestar contra su criterio jacobino, marxista o laico no obstante que los sistemas forales se hallan completamente libres de tachas parecidas". Además, para el autor era absolutamente rechazable la "tendencia separatista" de los peneuvistas, no siendo excusa el pretendido objetivo argumentado por ellos de "salvar al país vasco de la anarquía que le

36 Ángel García-Sanz Marcotegui, Diccionario Biográfico de los Diputados Forales de Navarra (1840-1931), op. cit., pp. 544-547. 
amenaza" de continuar unidos "a la politica y a la administración de la vigente política revolucionaria ${ }^{37}$.

Garrán consideraba la "restauración foral integra" en el caso de Navarra "como dificil o imposible por la mudanza de los tiempos y de las instituciones" ya que "mientras que las Juntas generales y Diputaciones forales vascongadas, pueden ser restablecidas quizá sin alteración, las Cortes de Navarra pudieran reproducirse con carácter ceremonial, pero sería dificil pudiesen funcionar con eficacia, o recobrar su antiguo arraigo" "no sólo por cuanto significan alteración de las organizaciones actuales, sino porque las clases sociales, costumbres politicas, y necesidades que les dieron origen, han variado por completo"38.

Garrán postulaba una actualización del entramado foral tradicional, diferenciando vías separadas para las Provincias Vascongadas y para Navarra. Para las primeras propugnaba el restablecimiento de las Juntas Generales y de las Diputaciones Forales, gozando de cada provincia de pleno poder legislativo y de plenas facultades. Un Consejo General Vascongado, integrado por "dos o tres, cinco a lo sumo" representantes por provincia, tendría como función "la representación ordinaria de las tres provincias ante el Estado", lo que no impediría cada provincia pudiera negociar "separadamente, con el Estado, cuanto le convenga en asunto ajeno a la mancomunidad" y entendería de las materias comunes a las tres provincias, materias que las mismas estimaran conveniente ejercerlas mancomunadamente. Por consiguiente, el Consejo General carecería de poder legislativo, que seguiría en manos de las tres Juntas generales por cuanto para el autor "no existe el Estado Vasco, sino tres provincias autónomas confederadas". Como mucho, el Consejo General "podría dictar reglamentos y expedir circulares para dirigir y administrar los asuntos de su competencia, pero sometiendo los estatutos y sus reformas a la aprobación de las provincias mancomunadas"39.

En el caso de Navarra, se limitaba a señalar el restablecimiento del poder legislativo encarnado en el Consejo Foral Administrativo por imposibilidad de resurgimiento de las Cortes navarras por su composición estamental ${ }^{40}$.

En relación con las relaciones con el Estado, tanto para las Vascongadas como para Navarra, planteaba la instauración del derecho de sobrecarta, el pase foral y el recurso a la inhibición, así como la estructura del Estado como unión a partir de la monarquía ${ }^{4}$.

El proyecto de Garrán convocaba a la colaboración entre carlistas y nacionalistas en defensa de la catolicidad, como con el Estatuto de Estella de 1931, y criticaba a los segundos por "recoger las teorias de Rousseau y Carlos Marx" y por haber "dejando de ser restaurador, ni conservador, mudándose en perturbador en teoría y revoltoso en la práctica, formando conciertos y alianzas

37 Justo Garrán y Moso, El sistema foral de Navarra y Provincias Vascongadas, op. cit., pp. 15- 17 .

$\begin{array}{ll}38 & \text { Ibid., p. } 47 . \\ 39 & \text { Ibid., pp. 124-128. } \\ 40 & \text { Ibid., pp. 237-240. } \\ 41 & \text { Ibid., pp. 255-257. }\end{array}$ 
con todos los elementos más díscolos y subversivos"42. Desde su punto de vista, la politica republicana de "concesión sucesiva a las regiones de los conocidos Estatutos" "no tenía más objeto sino ampliar los principios radicales y marxistas, a las regiones mejor dispuestas para rechazarlos"43. No obstante, insistió en la necesidad de reclamar con ahínco desde los parámetros del foralismo tradicional ante una hipotética revisión constitucional "cuantas facultades autonómicas sean precisas para defender la conservación de la familia, de la escuela, y del municipio cristianos", así como "los conciertos económicos y cierta autonomía administrativa", "nuestro derecho civil foral, y con él la conservación y autonomía tanto de nuestras instituciones agrarias, como de la escuela cristiana" 44 .

\section{ELADIO ESPARZA Y EL REINTEGRACIONISMO DURANTE LA REPÚBLICA. SU DEBATE CON JOAQUÍN BEÚNZA.}

Durante la República Eladio Esparza apenas se refirió al reintegracionismo como tal, según hemos comprobado tras repasar todos sus artículos en Diario de Navarra. Su mirada se dirigió primordialmente contra el estatutismo repúblicano, no solo contra el común con las Provincias Vascongadas sino incluso contra el exclusivamente navarro, tal y como mostramos hace unos años ${ }^{45}$.

Sus posiciones quedarian compendiadas en su libro Discurso sobre el Fuero de Navarra ${ }^{46}$, producto de una conferencia que impartió el 13 de abril de 1935 en un ciclo organizado por el Ateneo Navarro "sobre los problemas de fueros o autonomía de Navarra en los momentos actuales" en el que intervino también otra decena de expertos, entre ellos Joaquín Beúnza. Ese libro fue galardonado en mayo de 1936 (Diario de Navarra de 17 de ese mes) con el Premio del Libro Foral de Navarra de la Biblioteca Olave.

En él se retomaban reflexiones ya apuntadas años atrás como sus dudas sobre el interés de los navarros por el Fuero por la falta de análisis sobre el mismo; la falta de sentido del concepto de Reintegración Foral por ser el Fuero, literalmente hablando, de otra época; el sesgo separatista de interpretarlo de determinada manera; el Fuero "como expresión de la voluntad colectiva de nuestro pueblo", voluntad corporeizada a través del pacto, tanto el del siglo XVI de la unión con Castilla como el que dió lugar a la Ley de 1841; la lectura positiva de la unión eqüeprincipal de 1515; la interpretación de la solución cuarentayunista por la dificultad de adaptación a los tiempos modernos del régimen foral navarro; 47 y la legitimidad del pacto de 1841 porque respondió "a la demanda de todo el país que imperiosamente pedía, antes que otra cosa, poder vivir", negando que en 1839 Navarra fuera Reino independiente porque era "Reino distinto, como efectivamente lo era, dentro de aquel mosaico de Reinos que era

\footnotetext{
42 Ibid., pp. 263-267.

43 Ibid., pp. 267 y 279-280.

44 Ibid., p. 286.

45 Fernando Mikelarena,
} Navarra", op. cit., pp. 436-451.

"Navarra: entre el estatuto vasco y un estatuto singular para

46 Eladio Esparza, Discurso sobre el Fuero de Navarra, Pamplona, Ediciones Príncipe de Viana, 1935.

47 Ibid., pp. IIIv-IVf, Vv-Vir, Vir-VIIv, VIIr-VIIv, VIIIr-Ixv. 
España"48. Al hilo de ello, atacaba el reintegracionismo asegurando que "la reintegración foral absoluta y plena me parece el camelo foral absoluto y pleno" porque sólo sale a relucir "en momentos graves de nuestra vida política" y "después nada"49.

Asimismo, también insistió en la condición inferior del Estatuto en relación con el Fuero, algo que había anticipado en un artículo el 27 de octubre de 1933. Tras aseverar que el proceso estatutario de 1932 fue una "maniobra politica" del nacionalismo y del izquierdismo bajo el paraguas de la Constitución, apuntó a la primacía de los pactos forales históricos frente a cualquier vía estatutaria, siendo "indiscutible e indiscutido que sin Constitución y sin Estatuto, Navarra ostenta su derecho, aquel derecho que juraban los Reyes para poder ser Reyes de Navarra". De esta forma, Esparza no encontraba "en el Estatuto categoria bastante para Navarra" al ser "un huésped, de mestizo linaje, de no bien probada alcurnia" y que, además, conllevaba "un excesivo gravamen en su sostenimiento que no responde al honor de quien lo recibe"50. A nivel propositivo, planteaba en relación con el Fuero "conservar lo que se posee, mejorándolo y ampliándolo en cuanto sea posible" 51 .

Esas tesis sobre la condición inferior de Estatuto frente al Fuero enlazaban con las tesis defendidas por Víctor Pradera. En El Pensamiento Navarra de 11 de abril de 1933 se recogía el contenido de una conferencia de esta personalidad del tradicionalismo impartida en Pamplona. En ella contraponía la Constitución Interna de las naciones que "está en lo íntimo de la nación misma" con la Constitución republicana que no estaba "en armonía con aquélla" y que de, de forma similar, "la región tiene una ley fundamental que afecta a su pueblo privativo. En España esa ley fundamental regional la hemos llamado siempre fuero", concedida por "la Historia", mientras que "los estatutos no son nuestros, sino de quienes los dan. ¡Que se queden con ellos!”. Asimismo, incidia en el carácter laico de los estatutos, algo ya acordado "en el pacto de San Sebastián", lo que no se avenía con "las libertades forales, que estaban como empapadas precisamente en catolicismo".

A finales de 1935 y durante la primera mitad de 1936 tuvo lugar en la prensa navarra una polémica entre Eladio Esparza y un tal Miguel Ramón, uno desde Diario de Navarra y el otro desde El Pensamiento Navarro. A pesar de que varios autores ${ }^{52}$, incluido el autor de este trabajo, haciéndose cargo de la misma, no identificaron al segundo, hemos podido saber que se trataba del abogado y político tradicionalista Joaquín Beúnza, la persona, como ya se ha dicho, más

\footnotetext{
48 Ibid., pp. Xir-XIIv y p. XIXv.

49 Ibid., pp. XIIIv-XIVr.

50 Ibid., pp. XIVv-XVr.

51 Ibid. pp. XVv-XVIIr.
}

52 Jesús María Íbero Martinez, “Amejoramiento o Estatuto: una polémica dentro de la derecha navarra (mayo-julio 1936)", Príncipe de Viana, Anejo 10, 1988, pp. 183-190; Fernando Mikelarena, "Navarra: entre el estatuto vasco y un estatuto singular para Navarra", op. cit., pp. 451-457. Por contra, ni Santiago de Pablo Contreras ("Navarra y el Estatuto Vasco de la Asamblea de Pamplona al Frente Popular (1932-1936)", Príncipe de Viana, 184, 1988, pp. 401-414) ni Manuel Ferrer Muñoz ("La cuestión estatutaria en Navarra durante la Segunda República”, op. cit., pp. 197-224) mencionaron ese debate ni hablan para nada de la reivindicación reintegracionista ni de su subsunción por parte carlista en la vía estatutaria. 
cualificada en temas jurídicopolíticos del carlismo navarro. El 8 de septiembre de 1936, al informar de su asesinato en Guadalupe, El Pensamiento Navarro adjuntaba una biografia del mismo en la que especificaba que aquel nombre era el de su padre, utilizándolo Beúnza como seudónimo en sus colaboraciones en dicho periódico durante los años anteriores. Ese mismo dia Eladio Esparza se referira a la polémica que había mantenido con él empleando aquel seudónimo.

En la discusión Esparza rechazó las tesis de Beúnza, que no eran privativas de este, sino que, como se ha visto más arriba, coincidian con las oficiales de la Comunión Tradicionalista a partir del otoño de 1932, de apoyar un Estatuto navarro que sirviera para recuperar competencias homologables a las que se conseguirían con la Reintegración Foral.

En este contexto dio comienzo la discusión entre Esparza y Beúnza. El 27 de mayo el primero remarcaba, conforme sus tesis, que "Estatuto no es lo mismo que Fuero", y "que si Navarra opta por el Estatuto, Navarra reniega de su derecho foral, de su régimen de toda la vida, de su historia secular y hasta de su nombre".

Frente a ello, Beúnza replicaba al día siguiente que "la reintegración foral, es colocarse en la verdadera tesis del navarrismo" al ser "nuestro derecho secular" y lo que se nos debe "en justicia estricta". No obstante, señalaba que ese derecho había sido negado por todos los gobiernos y que habia habido "que transigir con la Ley del 41 y la del 77 y la del 27 y tantas otras que si mejoraban algo nuestro régimen, no eran, sin embargo, lo que Navarra deseaba como reconocimiento de nuestro derecho". Bajo todo ello, Beúnza apelaba a la posibilidad en "las circunstancias actuales" de "ampliar considerablemente las facultades de Navarra" y "obtener (...) la mayor suma" de ellas, dejando el menor número posible pendientes de una reconquista posterior", sin que esa obtención de una mejora parcial supusiera ninguna renuncia "a un mejoramiento futuro". También relativizaba la cuestión del nombre de "Estatuto si ha de encajar en el marco de la Constitución" si se obtenian dichas facultades, aun cuando él prefería emplear el término de Carta Foral.

Frente a una réplica poco enjundiosa de Esparza el día 29, el 30 Beúnza subrayaba la conveniencia de la reintegración de facultades que ofrecía el marco constitucional y relativizaba la importancia de la cuestión nominal: "Para el Estado será Estatuto; para nosotros Carta Foral, menos que Fuero, una especie de Fuero reducido o disminuido; pero además de una reivindicación parcial de nuestros derechos desusada por su amplitud, será el primer jalón para las demás reivindicaciones futuras, porque nuestra mejora de hoy no llevará aparejada ninguna renuncia ni total ni parcial para lo futuro". Beúnza recomendaba a Esparza olvidarse de escrúpulos ya que el Estado, por medio de la Constitución, ofrecía una devolución de facultades, sin pedir nada a cambio a través de un pacto, pudiéndose regresar al estado anterior en caso de no conveniencia.

En su respuesta del día 31, Esparza llevaba su negatividad al extremo al afirmar, mostrando su escepticismo sobre la facultades que podrían recuperarse, e indicando que Navarra no tenía "necesidad de acordar organizarse en región autónoma" conforme a la Constitución "porque ya lo es desde siempre ni tiene necesidad de desfigurar sus características autonómicas porque las tiene propias" y porque el pacto foral de siempre estaba por encima del pacto estatutario. 
El 7 de junio Beúnza exponía de nuevo los argumentos ya mencionados, advirtiendo de la distorsión que iba a crear en Navarra la concesión del Estatuto Vasco y recalcando que el pacto estatutario con Navarra sería diferente porque, mientras las demás regiones "deberían su autonomía exclusivamente a la Constitución", aquel partía del "propio pacto de su incorporación a Castilla, por el reconocimiento de su régimen peculiar a través de todos los Gobiernos que ha tenido España y en todas las épocas de su vida" y supondría un "reparo parcial de un agravio causado a la misma desde la Ley de 1839", así como la vía de acercamiento "todo lo posible a la reintegración foral completa".

Dos días después, el 9, Esparza repetía sus razonamientos y reconocía cuáles eran sus "temores en este asunto": "hacer simpática en Navarra la aceptación del Estatuto" e "incorporar a Navarra al estatuto vasco", llegándose así "al fin vilipendioso de Navarra, como personalidad histórica dotada del derecho propio de pactar". Asimismo, el dia 10 presentaba una propuesta de un nuevo pacto con el Estado, añadiendo a las materias forales pactadas en 1841 las no pactadas, mediante una negociación encabezada por la Diputación. Los límites de esa reforma serian "el estado actual como mínimo y la reintegración absoluta como máximo", siempre teniendo en cuenta las disponibilidades económicas. Con todo, alertaba por si "esto de la reintegración foral, (...), es en nuestra conciencia y en nuestra intrepidez de abolengo algo más que una palabra rimbombante y solemne mediante cuyo opio hemos distraído el problema desde el año 1839".

Asimismo, el 13 el lesakarra opinaba que, participando la región autónoma resultante del estatuto parte integrante "del ordenamiento jurídico del Estado, según la Constitución vigente", aquella no podría legislar en sentido contrario a la misma en cuestiones relativas a la religión y a la iglesia católica y a sus asociaciones e instituciones, debiéndose de regir el divorcio y la enseñanza laica. Esa actitud era rechazada por Beúnza que el 21 de junio indicaba, entre otras cosas, que siendo la reintegración foral "nuestro derecho perfecto", al no poderse conseguir, estaba a favor de conseguir la máxima autonomía para Navarra incluso de "una Constitución laica y con un régimen que vive inspirado en el espíritu antirreligioso de la misma".

E1 23 de junio Esparza daba por finalizada la polémica, afirmando que había interesado a muchos. Discrepaba de la afirmación de Beúnza sobre la inexistencia de pulso en Navarra desde la llegada de la República y lo hacia con unas palabras que anticipaban la movilización a rebato de las derechas navarras en pro del golpe de estado de un mes después. "¡Nuestra juventud”, señalaba, "viene con grandes arrestos y con el signo magnifico de un gran denuedo por el combate que será ineludible librar!. Confío tanto en nuestra juventud que creo que ha llegado la hora de que nuestras prudencias inadecuadas dejen de echar plomo en sus alas y de poner freno a su corazón".

No obstante, desde unos dias antes el tema había virado en otra dirección. El 17 de junio Esparza había publicado un artículo sobre la petición del Frente Popular Navarro de dos dias antes para que no desapareciera del proyecto de estatuto vasco el artículo que permitía a Navarra la inclusión en Euzkadi. Esparza acusaba a "los nacionalistas, los izquierdistas, los comunistas y los socialistas" de "destruir a Navarra" con esa propuesta. Al dia siguiente, Esparza volvía a atacar el apoyo de los nacionalistas al estatuto sujeto a "una Constitución laica, sectaria y sovietizante". 
Un mes más tarde, el 30 de julio, Esparza reconocería en un artículo publicado en la sección Estampa Foral que su refutación de la vía estatutaria tenía que ver en "verdad lisa y llana", en "verdad sincera y firme", con que "combatíamos el espíritu sectario y soviético de aquella Constitución anticatólica que engendraba los Estatutos, como tumores repletos de su mismo pus que habian de pudrir las regiones que lo aceptasen".

\section{LAS POSTURAS DE OTROS REPRESENTANTES DE LA DERECHA CONSERVADORA NAVARRA.}

Además de las posturas vistas anteriormente de Esparza y de Beúnza, otros autores vinculados con la derecha conservadora no tradicionalista navarra también se hicieron eco de la búsqueda de fórmulas que garantizaran la pemanencia del régimen foral navarro, aunque sin esgrimir apelaciones reintegracionistas.

En una carta publicada el 1 de octubre de 1932 en Diario de Navarra Pedro Uranga, abogado y exsecretario de la Diputación, muy ligado al consejo de administración de ese periódico, defendia aspirar "no a cualquier Estatuto sino a un Estatuto que respete nuestras características diferenciales y que se detenga ante la plenitud de nuestras facultades forales, las que tenemos hoy y las que el Estatuto nos otorgue". Reconociendo que la mayoría de los navarros estarian conformes "en la unión con las provincias vascas", afirmaba no estar de acuerdo con "la absorción por el país vasco" por recelar de "la locura de los renegados de España declarados o encubiertos" y de que "no se respete en la unión el derecho de los navarros a gobernarse libremente". Con todo, su propuesta era de un texto estatutario vasconavarro, aunque de minimos: "Nada de Parlamento regional que habria de nutrirse de la sustancia de nuestra autonomía: una simple Junta Central, lazo de unión, órgano de representación", "facultades para las respectivas provincias; derecho de delegados de la Junta Central o si se prefiere, también a otras que puedan constituirse con la mayor libertad; facultad natural de reconocer lo que se delega; y en lo demás un Estatuto acomodado a nuestra sencillez y a nuestras necesidades para incorporar lo que nos convenga y no más”.

El 4 de octubre los diputados navarros en Cortes Aizpún y Gortari, ambos conservadores y que unos meses antes se habian manifestado a favor del estatuto vasconavarro, se manifestaban partidarios "de pedir nuevas facultades autonómicas para Navarra", considerando "propicia" la ocasión, con la finalidad de "procurársenos algún alejamiento de las medidas sectarias y socializantes que predominan actualmente en la legislación general". A su juicio, "Navarra debe recabar facultades claro está que sin olvidar ni un momento las que tiene; pero sin que esto sea obstáculo para disponerse a pedir una mayor autonomia". Sobre la cuestión de solicitar un estatuto navarro o uno común con Vascongadas, "un aspecto difícil y vidrioso de la cuestión", y considerando que la Constitución prohibía la federación de regiones, planteaban como mejor solución, en línea con Uranga, "la creación de un órgano general que uniese formalmente las provincias en región, pero que no olvidase la personalidad de las provincias, ni mermase su libertad, ni absorbiese sus competencias. Un órgano, con facultades verdaderamente delegadas. Con ello, además, queda el camino libre para llegar hasta donde la voluntad de las provincias quiera, en ese aspecto de la potestad 
atribuída a ese órgano de enlace". A la luz del artículo 1 del decreto de 8 de diciembre que hablaba de ampliación de las competencias vigentes, consideraban equivocadas aquellas opiniones "de que presentando a las Cortes un proyecto de Estatuto podemos ver mermadas nuestras actuales facultades". Con todo, remarcaban que lo adecuado seria que, antes de someter a las Cortes el Estatuto, se garantizara que el status actual no se debía "poder mermar sino ampliarse" y para "lograr esa determinación del punto de partida autonómico" había que "tratar con el Gobierno". Fijada esa cuestión, el estatuto debía "acomodarse a dos moldes: Uno, nuestro régimen privativo (la actual autonomía), y otro la Constitución" de forma que "las Cortes concediesen al Gobierno una autorización para fijar de acuerdo con Navarra y las Vascongadas su Estatuto en armonía con su régimen especial, y luego, cumpliéndose, claro está, todo lo que la Constitución establece, someterían ese Estatuto, el Gobierno y las provincias, a la aprobación de las Cortes". "Con ello se aseguraria, hasta donde razonablemente cabe prevenir, el respeto a nuestro actual estado jurídico que es de donde nosotros tenemos que partir, porque en la realidad, la discusión en las Cortes de ese respeto y de ese punto de partida, además de no corresponderles, sería expuestísima. En cambio ante el Gobierno, con nuestro derecho por delante que ha sido reconocido por las mismas Cortes Constituyentes; con los precedentes que pueden invocarse; con nuestro sistema económico constituído y a base del cual viven la hacienda provincial y las haciendas municipales; con el trastorno enorme que el cambio de todo eso produciria sin ventaja alguna para el Estado, es fácil que las conversaciones serenas, meditadas, imparciales, dieran por resultado lo que es casi imposible de lograr en una Asamblea legislativa, donde, por necesidad, prevalece casi siempre el matiz político de los asuntos". "Y si se lograse eso, para nosotros, suponía una tranquilidad enorme; porque autorizado el Gobierno para convenir el Estatuto (aunque, claro está, había de ser sometido a las Cortes) iba ya el problema encarrilado y por quien había de encontrar en las Cortes evidentes facilidades".

Posteriormente en el ciclo de conferencias organizado por el Ateneo Navarro "sobre los problemas de fueros o autonomía de Navarra en los momentos actuales" entre finales de febrero y mediados de mayo de 1935, Uranga varió su postura de octubre de 1932. Acerca de "las perspectivas que ofrece la Constitución de la República a pueblos como el nuestro, de tradición autonómica y de aspiraciones a una mayor suma de facultades" apuntaba que él advertía un sólo peligro "en la constitución de la región autónoma", el "que se pone sobre la mesa del Congreso y expuesto a revisión, nuestro cupo foral, aventura que sería temerario correr sin las naturales cautelas". Ante ello, Uranga planteaba, en línea con la postura de Aizpún y Gortari, la necesidad de "un acuerdo previo con el Gobierno, que sería base para la propuesta de nuestros Ayuntamientos y para el plebiscito, y que el Gobierno podría llevar después como acuerdo y proyecto suyo a las Cortes, donde tendría así, naturalmente, la mayoría del Parlamento". Sobre las "ventajas de constituir solos o en unión de las provincias vascas una región autónoma" insistió en que el tema nuclear estaba ligado a la ubicación de las facultades de los navarros y al carácter de su delegación porque si "esas delegaciones o poderes son irrevocables, eso no sería ya delegación, sino la abdicación de Navarra". Lo mejor, a su juicio, era "en cuanto a nosotros, región navarra, soberanía, y una mancomunidad para las obras, servicios o funciones que se convinieran con las provincias vascas". 
Para Javier Arvizu, exdirector de El Demócrata Navarro y de El Pueblo Navarro, secretario de la Caja de Ahorros de Navarra y exalcalde de Pamplona entre febrero de 1930 y abril de 1931, los objetivos eran menos ambiciosos: por un lado, "poner término, mediante la oportuna revisión de las fuentes actuales de su Derecho positivo foral -ley de 16 de Agosto de 1841 y los convenios de 4 de noviembre de 1925 y 12 de Agosto de 1927- a las constantes transgresiones de nuestro régimen que realiza el Estado, a menudo más por desconocimiento que por mala voluntad"; por otro, "en esas Constituyentes que ya se anuncian y que han de cambiar la Constitución actual para llevar a ella los legítimos anhelos nacionales" el objetivo sería "incorporar al nuevo Código un precepto que consagre sustantivamente y para siempre el respeto a nuestro régimen foral”. A esas palabras recogidas por Diario de Navarra, El Pensamiento Navarro añadia que, siendo contrario el conferenciante a la Reintegración Foral, apoyaba "una autonomía plena solamente en el orden administrativo pero nada de autonomía en el político" en la que la ampliación de facultades descansase en "una ordenación pactada, a la que habría de llevarse como creación sustantiva un órgano expresivo, definidor y rector de nuestra soberanía foral; que podría ser el Consejo Administrativo, basado en el sufragio orgánico, con mayoría predominante de representantes municipales y la amplitud necesaria en los demás para que en él resultase reflejada toda la opinión del país".

De forma llamativa, una postura en cierta forma similar defendió el periodista e historiador Jesús Etayo que del jaimismo reintegracionista había pasado al nacionalismo. Aunque abogaba por la fórmula de la "reintegración foral completa", la dejó de lado "porque no estamos en coyuntura de recabar la reintegración que brinda el panorama de la politica española". Subrayando el error que había constituído el rechazo del estatuto vasconavarro, reconoció no atreverse a proponerlo otra vez. Apuntó que "la anunciada reforma de la Constitución" mediante la prevalencia de "la inspiración de las fuerzas politicas españolas que se llaman de Centro Derecha" conllevaria que "las posibilidades autonómicas serán menores" dado el carácter centralista de aquéllas. Con todo, expresó la posibilidad de que "nuestro régimen pueda ser revisado y mejorado con ocasión de la reforma constitucional" por la vía de que "de modo expreso se consignara en la Constitución una referencia al régimen foral existente en Navarra, y la posibilidad legal de que en todo momento pudiera ser objeto de modificación mediante convenio, concierto o acuerdo entre la representación del Estado y la de Navarra". "Consignado eso en un párrafo, cuanto más breve mejor, en la Constitución, en Navarra deberíamos estudiar no sólo la aclaración, para consolidarlas, de las facultades que ya ejercemos, sino cuáles otras podriamos recabar". Sobre esa última cuestión, apuntó que su aspiración "no tendría límite", pero que quería "reducirla al minimum", señalando que se deberían "recabar, mediante acuerdo con el Estado, subsiguiente a la consagración en la Constitución de un régimen especial para Navarra, facultades autonómicas respecto a estas materias: Legislación Civil, Administración de Justicia, Enseñanza y Política agro-social”.

Por último, Pelayo Moreno, secretario de Unión Navarra, el partido hermano de la CEDA en Navarra, coincidió en buena parte con Arvizu y con Etayo. Se refirió a las posibilidades que abría la posibilidad cierta de la revisión próxima de la Constitución, y que, su juicio, debía llevarse a la misma "el reconocimiento del régimen foral existente en Navarra", lo que acarrearía 
"las siguientes ventajas: la garantía de que el respeto a nuestro régimen tuviera rango constitucional; la mayor dificultad en los ataques al fuero por parte del Poder Central ya que éste, al dictar una disposición que afectase a Navarra miraría con más cuidado si tal resolución afectaba y violaba nuestro Fuero, no por respeto al Fuero mismo, sino por respeto a la Constitución que lo reconocía y amparaba; en el caso de que se consumase un contrafuero, la posibilidad de repararlo entablando el recurso de inconstitucionalidad que autoriza la Ley del Tribunal de Garantías creado por el artículo 122 de la vigente Constitución". En el supuesto de que se consiguiera dicho reconocimiento constitucional, se debia "plantear (...) la revisión del régimen autonómico de Navarra, partiendo, como mínimum, de su estado de derecho actual y ampliándolo cuanto sea posible, pero siempre dentro de aquello que convenga a nuestra tierra". Las facultades que podrían ampliarse serían "todas las atribuciones que dicen relación a la legislación civil, a la administración de Justicia, a la enseñanza, a la beneficencia y Sanidad y a la politica agraria", sin que dicha relación tuviera "un valor taxativo, sino meramente enumerativo", ni comprendiera "todas aquellas atribuciones que debemos recabar al plantear el problema de la revisión de nuestro régimen". A su juicio, Navarra debía "recabar la facultad de darse a sí misma su propio derecho, dentro de los límites impuestos por la soberanía nacional española. Y lo mismo podemos decir del órgano encargado de la aplicación e interpretación del derecho positivo". Bajo su punto de vista, era "indiferente el nombre que se dé al documento en que conste la nueva construcción de nuestro régimen foral. ¿Ley paccionada? ¿concordia? ¿acuerdo? ¿pacto? ¿ordenación foral? ¿Estatuto Navarro? Cualquiera de ellos es bueno, siempre que en él subsistan de forma clara, estable y eficaz los derechos forales de Navarra y se asiente sobre bases firmes el respeto a los mismos y a ser posible su intangibilidad. Y digo Estatuto Navarro, porque Navarra debe ir sola para la mejor defensa de sus intereses y sus privilegios esencialmente distintos de los de las provincias Vascongadas".

\section{ELADIO ESPARZA Y LA REINTEGRACIÓN FORAL PARCIAL TRAS EL GOLPE DE ESTADO DE JULIO DE 1936.}

Inmediatamente después del golpe de Estado de julio de 1936, del que Navarra fue, como es sabido, epicentro primordial, personalidades como Eladio Esparza (auténtico hombre fuerte en aquellos meses y años pues, a su trabajo como subdirector de Diario de Navarra, hay que añadir que fue Delegado de Prensa del Requeté navarro junto a López Sanz en julio y agosto de 1936, Secretario de la Junta Superior de Educación, Secretario General de Prensa del Gobierno de Salamanca en mayo de 1937 y Gobernador Civil de Álava entre agosto de 1937 y septiembre de 1938) idearon poner en práctica una versión reduccionista de la Reintegración Foral por medio de la resurrección de diversas juntas que, bajo el manto de la Gestora de la Diputación Foral completamente derechista surgida de un proceso electoral indirecto de enero de 1935 con una treintena de ayuntamientos de izquierda o nacionalistas suspendidos ${ }^{53}$, suponían la atribución unilateral de facultades competenciales sobre diversas materias. De

53 Ángel Pascual Bonís, "La actividad de las gestoras de la Diputación Foral (1931-1939) y sus relaciones con el poder central”, op. cit, pp. 459-462. 
esta forma, el 29 de julio Esparza, con ocasión del acuerdo de la Diputación sobre la reposición de crucifijos en las escuelas y sobre otros aspectos educativos, expresó en su sección de Estampa Foral de Diario de Navarra: "Es preciso remontarse en nuestra historia hasta la soberanía de cuando era Reino para encontrar en su legislación algo en que con este acuerdo se enlace!. Y veáse cómo, no ya dentro de la unidad de la Patria, para Navarra indiscutible siempre, sino en la hora emocionante en que Navarra pone en pie de guerra a sus hombres para salvar a España, es posible esta reintegración foral, tal plena y satisfactoria para nosotros y que será en España ejemplo".

A lo largo de las semanas siguientes, la Diputación, apoyando la idea, impulsó el 11 de agosto la constitución de la Junta Superior de Educación, así como de la Junta de Reformas Sociales y de la Junta de Beneficencia el 29 del mismo mes. En relación con la primera de ellas, constituída en su totalidad por miembros de la derecha conservadora y tradicionalista y por profesionales de la educación de las mismas ideologías y en la que desde el 15 de agosto el mismo Esparza figuraría como Secretario de la misma, Diario de Navarra decía el 12 de agosto que, surgida con las Cortes navarras de 1828-1829, se había ahora restablecido. El periódico alababa la iniciativa y subrayaba los "fines restauradores de nuestro régimen privativo, lo más foral y parejamente lo más auténtico español de la Patria". Con ocasión de la conformación de las otras dos Juntas, Diario de Navarra afirmaria el 30 de agosto que "sigue la obra de restauración". Y el 6 de diciembre Esparza en su sección de Friso Rojo mencionaría los "afanes restauradores" de la Diputación desde el 19 de julio.

De esas tres Juntas la más importante fue la primera. A través de dicha Junta, la gestora de la Diputación asumió en su integridad todas las decisiones en materia educativa en cuanto a la organización y régimen de la Enseñanza Primaria de Navarra, al principio, y de los demás niveles educativos después; nombramientos de maestros y depuración de los ya existentes; planes de estudio y control de los mismos; calendario escolar; horarios; textos; etc ${ }^{54}$. Dicha Junta Superior de Educación emprendería una radical recatolización de la enseñanza en Navarra y un castigo implacable a todos los maestros y profesores simpatizantes de la República. Navarra se adelantó en esas medidas "a la Junta de Defensa Nacional de Burgos, en meses y aun en años"55.

En cambio, la Junta de Reformas Sociales y la Junta de Beneficencia "apenas actuaron". La primera surgió para garantizar la recta enseñanza y educación de la juventud de acuerdo con los parámetros del catolicismo social, pero dicho propósito no se sustanció en nada. Dos meses más tarde, a finales de octubre de 1936, dicha Junta se dividió en dos: una con el mismo nombre de la matriz y otra denominada de Reforma Agraria, esta última encargada del estudio de los problemas sociales del agro navarro (Aprovechamientos de las grandes propiedades; Solución al problema de las corralizas; Rescate y justo aprovechamiento de los comunes; Patrimonio familiar inembargable; Regulación de los arrendamientos rústicos; etc.) ${ }^{56}$. Con todo, "sobre las materias señaladas la

\footnotetext{
54 Ángel Pascual Bonis, "La actividad de las gestoras de la Diputación Foral (1931-1939) y sus relaciones con el poder central”, op. cit., , p. 479.

55 Ibidem.

$56 \quad$ Ibid., pp. 476-477.
} 
Gestora no tomó un solo acuerdo en los tres años de guerra y la nueva Diputación que le sustituyó (nombrada por el Consejo Foral el 16 de mayo de 1940) acordó el cese de las Juntas citadas"57.

En su afán de ampliación de competencias la Gestora de la Diputación llegó a ir más allá de lo que había admitido el poder central republicano en cuanto a las facultades de aquellas para imponer derechos de cobro de impuestos directos. Así, el 29 de julio de 1936 acordó mantener para Navarra el derecho a cobrar el Impuesto sobre la Renta, que había intentado implantar en 1935 en virtud de lo que decía el convenio económico de 1927, y que le había sido denegado por una Orden gubernamental de doce dias antes ${ }^{58}$.

En relación con todo ello, Ugarte Tellería ha mencionado que de esa manera surgió "un verdadero poder para-estatal o cuasi-estatal en zona rebelde vasconavarra, autónomo en buena medida de las directrices de Salamanca, con un proyecto de régimen propio (...) y un poder notable para sacar adelante su proyecto (...) un País Vasco-Navarro nacional-corporativo y foral", pudiéndose "probablemente hablarse de la existencia durante unos años en el País VascoNavarro de un cuasi-Estado nacional-corporativo y foral-católico"59. No obstante, discrepamos de ese autor en que, en virtud de las Juntas resucitadas y de su operatividad, se pueda hablar de que los gestores de la Diputación tratasen de conseguir la "reintegración foral plena"60 ya que esta conceptualmente significaba, tal y como hemos explicado, mucho más que aquello. Por otra parte, hemos encontrado rastros de que en aquella época algunos sectores del tradicionalismo trataron de impulsar una dinámica reintegracionista diferente y mucho más acorde con lo que que marcaba la ortodoxia del reintegracionismo convencionalmente considerado.

\section{INICIATIVAS REINTEGRACIONISTAS TRAS EL GOLPE DE ESTADO DE JULIO DE 1936.}

Es significativo que no fuera la Gestora de la Diputación, sino la Junta Central Carlista de Guerra de Navarra la que impulsara una Comisión de Expertos sobre la Reintegración Foral. Hemos de recordar que dicha Junta Central fue el órgano surgido el 20 de julio por propuesta del coronel Beorlegui a instancias de Mola y que estaba formado por carlistas relevantes que habian negociado separadamente con este, a espaldas de las autoridades nacionales del partido, y que asumiría la gestión de la movilización y de la limpieza política por el lado requeté, instalándose en el Palacio de la Diputación para que se visualizara la identificación entre Navarra y el tradicionalismo, a excepción de los servicios de alistamientos y de represión que se ubicarian en el Cuartel del Colegio de Escolapios ${ }^{61}$. Esa Junta Central acordó la creación de dicha Comisión

\footnotetext{
$57 \quad$ Ibid., p. 477.

58 Ibid., p. 476.

59 Javier Ugarte Tellería, "El carlismo en la guerra del 36: la formación de un cuasi-estado nacional-corporativo y foral en la zona vasco-navarra”, Historia Contemporánea, 38, 2009, pp. 51 y
} 84.

60 Ibid., en la p. 62 hay algunas menciones de ello.

61 Sobre la Junta Central carlista de Guerra de Navarra, veáse, Fernando Mikelarena, Sin Piedad. Limpieza politica en Navarra 1936. Responsables, colaboradores y ejecutores, Arre, 
en su sesión de 19 de agosto, concretando que "la reintegración foral significa el estado anterior a la ley de 25 de octubre de 1839". Designaron como expertos a Joaquín Beunza (entonces detenido en Guipúzcoa y que sería asesinado en el fuerte de Guadalupe dos semanas después), Luis Oroz Zabaleta, Justo Garrán, Pedro José Arraiza, Francisco López Sanz, Ignacio Sanz González y Juan Ángel Ortigosa. Debian dictaminar sobre las facultades de Navarra en materia de Instrucción y Enseñanza, Quintas, Organización Provincial y Municipal y Derecho Civil. Dicho acuerdo no generó ninguna reacción en la Gestora de la Diputación, si bien hay que decir que la labor de esa comisión no se concretó en nada ${ }^{62}$.

En relación con los perfiles de sus componentes solamente Beúnza y Garrán, como hemos visto, habían realizado aportaciones en relación con el tema. El que más se les aproximaba era Luis Oroz Zabaleta, filonacionalista en su juventud, posteriormente posicionado en el tradicionalismo y foralista convencido. Entre 1921 y 1945 fue secretario de la Corporación Foral. Participó en las negociaciones para la aplicación del Estatuto Municipal de 1924 a Navarra y en la elaboración del Anteproyecto del Estatuto General Vasco de 1931. En 1927 y 1941 intervino en la preparación y negociación de los Convenios Económicos con el Estado. Paralelamente elaboró, por encargo de la Diputación, el Reglamento para la Administración Municipal de Navarra. Su obra más importante es la Legislación Administrativa de Navarra, editada en dos tomos en 1917 y $1923^{63}$.

De los demás miembros de esa Comisión, no se conoce aportación alguna en relación con el status políticoinstitucional de Navarra. Pedro José Arraiza Garbalena era de una familia situada entre las élites socioeconómicas derechistas navarras. Era abogado y fue concejal de Pamplona en varias ocasiones (entre marzo de 1929 y enero de 1930, junio de 1931 y agosto de 1934 y febrero de 1937 y abril de 1940) ${ }^{64}$. Participó en mitines del Bloque de Derechas en la campaña electoral de 1933. Fue Presidente del Consejo de Administración de Diario de Navarra entre 1957 y 1959 (Diario de Navarra de 25 de febrero de 2003).

Ignacio Sanz Gonzalez fue secretario municipal del ayuntamiento de Pamplona desde 1927 hasta su jubilación en 1966. Entró en el cargo tras licenciarse en Derecho y trabajar de funcionario en la Diputación y de letrado en la Vasco Navarra (Diario de Navarra de 30 de julio de 1966). En 1933 era presidente de la Asociación de Secretarios de Ayuntamientos de Navarra y siguió siéndolo en los años cuarenta, en los años cincuenta y en los años sesenta. También fue miembro del Consejo Foral Administrativo en los años sesenta y setenta.

Juan Ángel Ortigosa Irigoyen, Licenciado en Derecho por la Universidad de Valladolid, comenzó a ejercer en 1927. Miembro de la Comunión Tradicionalista durante la República, participó en mitines de la formación ya en 1933 así como en el otoño de 1936. En noviembre de 1937 fue designado Jefe Provincial de FET y de las JONS. El 26 de noviembre de ese año Diario de Navarra reprodujo su

Pamiela, 2015, pp. 177-286.

62 Ángel Pascual Bonís, "La actividad de las gestoras de la Diputación Foral (1931-1939) y sus relaciones con el poder central”, op. cit., p. 482.

63 http://dbe.rah.es/biografias/65252/luis-oroz-zabaleta

64 Ángel García-Sanz Marcotegui, Diccionario Biográfico de los Diputados Forales de Navarra (1840-1931), op. cit., pp. 330-335. 
discurso de nombramiento repleto de consignas propias del nacionalcatolicismo franquista navarro y de loas al partido único. Permaneció en el cargo hasta finales de julio de 1938, siendo sustituído por Adolfo Goñi Iraeta, también tradicionalista, hasta entonces Jefe Local del Movimiento. En agosto de 1939 fue nombrado subsecretario del Ministerio de Justicia de la mano de Esteban Bilbao, cargo en el que estuvo hasta 1942. También fue Consejero nacional y procurador en las Cortes franquistas.

Francisco López Sanz Latasa (1896-1977) era periodista y escritor ligado al tradicionalismo. Ingresó en la redacción de El Pensamiento Navarro en 1917, siendo su director desde 1933 hasta su jubilación en 1964. Utilizó los seudónimos de Sab y Lopezarra. Participó en mítines carlistas y electorales. Fue junto con Eladio Esparza Delegado de Prensa del Requeté de Navarra en los primeros meses tras el golpe de Estado. Como escritor y articulista fue un férreo defensor del carlismo y un apologeta de la participación de Navarra en el golpe de Estado. Fue concejal del Ayuntamiento de Pamplona y presidente de la Asociación de la Prensa y recibió premios y condecoraciones del régimen franquista ${ }^{65}$.

Aunque esa Comisión para la Reintegración Foral no llevó a cabo ninguna iniciativa en relación con las tareas que le habian sido encomendadas, lo que se corresponde con la actitud de supeditación a Mola y a los militares en relación con el proceso de unificación de FET y de las JONS de la Junta Central que la había creado66, en el Consejo Foral Administrativo de 31 de mayo de 1937 se leyó, de forma sorprendente, teniendo en cuenta los tiempos que corrian, una moción de uno de sus componentes, el ya mencionado Ignacio Sanz González, que se refería a una revisión del status politico-institucional de Navarra ${ }^{67}$ y que nadie habia mencionado hasta ahora.

Esa moción pretendía en sus primeras líneas "estudiar el futuro de Navarra en su organización general" y aludía al próximo final de la guerra y a la creación de la nueva España, recogiéndose declaraciones de Franco y de Mola sobre que "España es, además, una unidad histórica que repudia los separatismos, aunque no la modalidad característica de sus regiones" y "Navarra desbordó el embalse, acumulado tenazmente durante los siglos, de aquella tradición española que no representa carácter alguno local ni regional, sino al contrario, universalista, hispano e imperial, que se habia conservado entre aquellas peñas inexpugnables, esperando el momento oportuno para intervenir y derramarse cantando fe inquebrantable en Dios y un gran amor a nuestra Patria". La moción expresaba la compatibilidad entre el amor de Navarra por su pasado y sus tradiciones en cuanto que "saben hermanarse con las normas modernas en cuanto se dirijen al mejor florecimiento nacional" y planteaba que "por lo tanto llega el momento de tener que pensar en los jalones que haya de poner Navarra para desenvolver en la paz lo que su precia personalidad mantiene y defiende sin limite en el sacrificio". Se decía que "en el orden político y en cuanto se refiere al organismo director de

65 http://www.enciclopedianavarra.com/?page_id=13401.

66 Sobre su supeditación a Mola y su actitud en el proceso de unificación, Fernando Mikelarena, Sin Piedad. Limpieza politica en Navarra 1936. Responsables, colaboradores y ejecutores, op. cit., pp. 177-202 y 286-294.

67 Archivo Real y General de Navarra (ARGN), Consejo Foral Administrativo, Caja 25461, Sesión de 31 de mayo de 1937. 
la vida administrativa, ha de armonizar su régimen conociendo de antemano las bases que servirán de norma al nuevo Estado, llevando siempre su fisonomía tradicional, lo que obliga a pensar en los órganos de gobierno, facultades propias, estructura de las municipalidades en régimen de máxima autonomía con máxima responsabilidad, en la separación de la facultad hoy confiada a la Diputación de resolver recursos, que habrá de confiarse a Tribunal especial, solvente según los principios en que se inspira siempre la administración de justicia”. También se refería a que "no puede menos de estudiarse la división territorial, la organización de Navarra en cuanto al aspecto social, tan de primer plano, previendo cuanto corresponda a los organismos rectores, organismos colaboradores, Tribunales, y seguros de todas clases, cuyo desarrollo puede ser para nuestra economía fuente de riqueza". Asimismo, se añadía que "Todo esto exige una actividad fecunda de estudios y trabajo, para que cuando llegue la estructuración definitiva del Estado, con sus leyes reguladoras sepa Navarra qué le interesa y cuál ha de ser su futuro, porque no es justo vivir en el cómodo sitial viendo pasar los dias, sin que la conciencia españolísima del pueblo navarro vea a los Organismos legítimos que la representan actuar en defensa de sus principios, que es la labor peculiar de los que ejercemos cargos de la responsabilidad confiada al Consejo Foral".

Finalmente, la moción pedía que se acordara "afrontar el estudio completo de la futura organización de Navarra con la amplitud completa, tanto en el orden económico-administrativo, como en el civil, cultural, etcétera, para que con los asesoramientos oportunos" se realizara "un indice de estudios y normas que llevadas a la práctica sean reguladoras del nuevo vivir, que sin cambiar lo tradicional en navarra, sepa ser adaptado a los nuevos modos de vivir dentro de la concepción totalitaria del Estado, que sabrá respetar modalidad tan peculiar como la navarra".

A ello se adjuntaba, y esto es tremendamente interesante, un "Indice de las Aspiraciones Autonómicas de Navarra" que decía lo siguiente, diferenciando la reintegración foral plena, como aspiración máxima $y$ con todas sus consecuencias, de la ampliación de facultades autonómicas, que se detallaban, dentro del marco entonces vigente derivado de una revisión del marco de 1841 .

Como "Aspiración Máxima" se planteaba la "Reintegración foral plena mediante el restablecimiento del estado de derecho anterior a las Leyes de modificación de Fueros de 25 de Octubre de 1839 y 16 de Agosto de 1841, que serían derogadas", añadiéndose que "para llevarla a efecto sería preciso la restauración de los organismos forales, y estos una vez constituídos, de acuerdo con el Gobierno, adaptarian a la época actual las relaciones de derecho con el Estado dentro de la unidad de la Nación Española".

A su vez, en cuanto a la "ampliación de las Facultades Autonómicas de Navarra" se decía que "las facultades autonómicas que actualmente disfruta Navarra en virtud de su régimen foral privativo, podrian extenderse sin menoscabo de la soberanía del Estado, a las materias siguientes: a) Administración local, comprendiendo todo cuanto se relaciona con la organización y régimen de la administración provincial y municipal y de los funcionarios y empleados de todas clases dependientes de la misma; b) Organización de un Tribunal especial de lo Contencioso-administrativo, para decidir sin apelación los recursos de este orden que se promovieran contra las decisiones de las Autoridades y organismos locales en materia foral; c) Revisión del derecho civil foral y aprobación del Apéndice de Navarra al Código Civil; d) 
Organización de la Justicia municipal, mantenimiento de la Audiencia Territorial y facultad de proponer el nombramiento de uno o más Magistrados del Tribunal Supremo, de reconocida competencia en el derecho foral, que intervenga en el fallo de los pleitos de esta clase que se ventilen ante aquel Tribunal; e) Enseñanza pública y privada en todos sus grados y especialidades; f) Beneficencia pública y privada; g) Baños y aguas minero-medicinales; h) Protección a la Infancia, Tribunales tutelares de Menores y Mendicidad; i) Régimen de montes, rescate, conservación y disfrute de la propiedad comunal y devolución a Navarra de todos los montes del Estado enclavados en su territorio; j) Régimen y fomento de caza y pesca; k) Agricultura, ganaderia, vias pecuarias y sanidad pecuaria; 1) Ferrocarriles, tranvias, carreteras, teléfonos, aeropuertos y radiocomunicación en cuanto no tenga interés nacional ni traspasen el territorio navarro; $\mathrm{m}$ ) Régimen de minas; n) Instituciones de ahorro, provisión y crédito organizadas por Corporaciones oficiales y Asociaciones domiciliadas en Navarra; o) Transportes por carreteras con un régimen de reciprocidad en cuanto a las lineas que traspongan los limites territoriales y policía de circulación por las mismas vias; $p$ ) Organización del guarderío rural como cuerpo armado al mando de Jefes Militares; q) Aprovechamientos hidraúlicos e instalaciones eléctricas dentro también del territorio navarro; r) Legislación social y de trabajo, Corporaciones sociales, económicas y profesionales de todas clases, sindicales y Corporativas, agrícolas y ganaderas. Política y acción agrarias; s) Compensaciones económicas a Navarra por el gasto que representen los nuevos servicios de que se haga cargo". Como se ve, un programa de ampliación competencial del marco de 1841 en el plano administrativo con la inclusión de garantías de la foralidad en el ámbito jurisdiccional.

En la reunión del Consejo Foral Administrativo sobre esa moción se acordó pasarla a la Comisión Permanente para que promoviera directamente ante la Diputación "las iniciativas que juzgue oportunas para que con la mayor rapidez pueda llevarse a cabo el estudio a que se refiere". No obstante, en un folio aparte figura que el 24 de julio se reunió la Comisión Permanente "para tratar de la forma en que podrian organizarse los trabajos a que se refiere la moción", trayendo "a la vista diversos antecedentes y entre otros una relación de temas o materias que habian sido objeto de estudio anteriormente, conviniéndose en definitiva en prescindir de la orientación señalada en aquellos trabajos y nombrar una Comisión compuesta de los Vocales de la Comisión Don Luis Ortega, Don José María Iribarren [Rodriguez] y Don Ignacio Sanz para que estudiasen la moción por este último presentada".

Asimismo, en ese folio aparte constaba que "uno de los Señores Vocales de la Comisión extraño a la Ponencia sin conocimiento de los Vocales de la Comisión ni de los Señores Diputados al entrevistarse con un periodista local de el Diario de Navarra le dio cuenta del nombramiento de la Comisión, facultándole a la vez, sin concederle importancia, una copia de la Relación de antecedentes vistos en la reunión cuya publicación ha dado lugar a que se haya interpretado equivocadamente lo tratado y resuelto en la mencionada reunión. Se deduce, en consecuencia, que ni por parte del Consejo Foral, ni de su Comisión Permanente, ni mucho menos por la de la Diputación que es la que cualesquiera que sean los informes y propuestas que en este punto se formulen ha de resolver en definitiva se han concretado aspiraciones forales de ninguna clase ni se han autorizado oficial ni oficiosamente, la publicación de nota ni acuerdo alguno sobre el 
particular en la Prensa". Esa mención tenía que ver con la circunstancia de que Diario de Navarra publicó el contenido de la moción el día 2 de junio sin mencionar el Indice de Aspiraciones Autonómicas después de haber informado la víspera superficialmente sobre la misma. Asimismo, el 25 de julio Diario de Navarra informaría de la reunión de la Comisión Permanente del dia anterior, reproduciéndose aquel Índice. Curiosamente en El Pensamiento Navarro también se reprodujo la moción el 1 de junio, pero sin el Índice de Aspiraciones que tampoco se reprodujeron en los días siguientes ni siquiera el 25 de julio cuando se publicó en Diario de Navarra. Tampoco consta nada en Arriba España, el periódico falangista.

Finalmente el asunto tampoco desembocaría en nada. Una nota de la Diputación, fechada en 7 de agosto de 1937, que figura en la misma documentación, revela que la misma se desentendía del asunto ya que dice:

"Esta Diputación se ha hecho cargo de la campaña que viene desarrollándose a propósito de una información publicada por Diario de Navarra con motivo de la reunión celebrada el día 24 de Julio por la Comisión Permanente del Consejo Foral para estudiar una moción presentada al mismo sobre futura organización de Navarra.

Habiéndose dado a lo tratado en dicha Comisión un alcance indebido esta Diputación estima necesario dejar las cosas en su lugar manifestando que el único acuerdo recaído en la citada reunión fue el nombramiento de una Comisión que ha de encargarse de estudiar la moción de referencia en la cual no se formulaban concretamente aspiraciones forales de ninguna clase, ni se concretaron tampoco en la reunión y que la relación publicada con el suelto aludido no es otra cosa que un índice de materias que se tuvo en cuenta en la citada reunión para organizar la Comisión que había de encargarse de los estudios sin que pueda dar por consiguiente valor alguno en el sentido indicado".

Con posterioridad a ello no hay ninguna huella documental de que el Consejo Foral Administrativo, en pleno o en el Consejo Permanente o en el Consejo de Expertos designado por este último, tratara el tema, con lo que la cuestión se diluyó.

El último acto sobre dicha iniciativa fue la entrevista que Diario de Navarra hizo el 11 de agosto de 1937 a Pedro Sainz Rodriguez, designado el 16 de julio anterior por Franco Jefe Nacional de FET y de las JONS, en la que en relación con "las reivindicaciones de Navarra de las que se ha hablado estos dias en algunos periódicos" el entrevistado decía que no había sido "más que una tempestad en un vaso de agua nacida de una mala información. Ni por parte de la Diputación ni del pueblo navarro se ha formulado sobre este particular ni petición de ninguna clase. La nota publicada en los periódicos no fue más que una información producida de la iniciativa de un señor que mandó a una Comisión una lista de temas de estudio sobre cuestiones forales, pero repito que ni el Consejo Foral tuvo participación en la publicación de esa nota ni ha habido cuestión de ningún género ni ella acusa en la forma en que está redactada las aspiraciones de ningún organismo de Navarra. ¿Cómo iba a responder esa lista a la doctrina tradicional, si en ella se habla de autonomía? La batalla doctrinal del tradicionalismo en la cuestión de la personalidad de la provincia ha girado precisamente alrededor de la interpretación de la palabra autarquía. Hablar de autonomía entre los tradicionalistas es cometer una herejía técnica de expresión. 
¿Qué hubiesen dicho Pradera y Vázquez de Mella si levantasen la cabeza y oyesen hablar de autonomia? Pero no haya cuidado, porque los tradicionalistas saben muy bien su doctrina y la cosa no tiene más trascendencia que la dicha”.

Por otra parte, tenemos que hacernos eco de un informe sobre la Reintegración Foral elaborado en marzo de 1939 por Luis Oroz Zabaleta, el secretario de la Diputación y miembro de la Comisión para la Reintegración Foral creada por la Junta Central Carlista de Guerra. Seguramente ese informe tiene que ver con el escrito remitido a la Gestora de la Diputación por el Subsecretario de Gobernación del Gobierno de Salamanca en el que solicitaba a aquella un informe sobre las necesidades y aspiraciones de Navarra, cuya satisfacción dependiera del poder central. La Corporación Foral, según consta en el acta de la reunión de 21 de aquel mes, resumía su aspiración en que el régimen foral derivado de la Ley Paccionada y ratificado en los Decretos-Leyes de 4 de noviembre de 1925 y 15 de agosto de 1927 fuera "fiel y escrupulosamente" mantenido y respetado. Se recordaba que tal promesa ya fue hecha en el Bando de Guerra del General Mola y que la misma idea figuraba en el Decreto-Ley de 23 de junio de 1937 por la que fueron suprimidos los Conciertos de Vizcaya y Guipúzcoa, recogiéndose la frase de Franco en el citado Decreto que mencionaba que "la singularidad del régimen fiscal y administrativo sirvió en algunas provincias, como la lealísima Navarra, para exaltar cada día más su sentimiento nacional y el fervor de su adhesión al común destino de la Patria..., como muestra de la gran consideración que el Caudillo manifiesta por los derechos forales". En su espíritu, la Diputación pedia el respeto del régimen foral en su versión cuarentayunista, sin perjuicio de las modificaciones necesarias para acomodarlo a la nueva situación, siempre que éstas se hicieran previo acuerdo con ella68.

Hemos localizado el mencionado informe de Oroz Zabaleta en el Fondo Fal Conde del Archivo General de la Universidad de Navarra. Se trata de un documento titulado "Problema foral de Navarra" en el que pegado al mismo está una tarjeta que reza "Francisco Armisén. Profesor Mercantil-Seguros". En el reverso consta "Trabajo del Secretario de la Diputación de Navarra Don Luis Oroz. Marzo 1939. Cumplido el encargo de J. Del Burgo-Janín”69.

La mayor parte del documento es una descripción "a grandes rasgos" de "las características principales del régimen politico de Navarra" hasta 1812. Anteriormente se dice en el inicio del mismo que "uno de los principios básicos y fundamentales del programa Tradicionalista, inspirado en las esencias históricas de nuestra Patria, es el de la restauración plena y absoluta de los Fueros", lo que había sido "proclamado constante y unánimemente" por "los Reyes en sus manifiestos, los Caudillos en sus proclamas militares, los pensadores y propagandistas en sus discursos y campañas". Seguidamente se explicaba que "ese postulado significa el restablecimiento del estado de derecho subsistente desde su incorporación [de Navarra] a la Corona de Castilla, llevada a cabo en las

68 Ibid., p. 485.

69 Archivo General de la Universidad de Navarra (AGUN), Fondo Fal Conde, Caja 277. Francisco Armisén era concejal tradicionalista de Pamplona. Benigno Janín era Inspector Jefe y Jefe de la Sección Administrativa de Primera Enseñanza y vocal de la Junta Superior de Educación, también carlista. Jaime del Burgo había sido Jefe del Requeté de Pamplona en los años republicanos. 
Cortes de Burgos de 1514, hasta la promulgación de la Constitución liberal de 1812, que, aboliendo el régimen político tradicional de la Monarquía española, implantó los principios unitarios y democráticos proclamados por la revolución francesa, puesto que hasta esa época, y aun más tarde, en los periodos del siglo pasado en que estuvo triunfante la Restauración, Navarra estuvo en posesión de todos sus derechos históricos, que desaparecieron con el triunfo del sistema constitucional".

Tras describirse entre las páginas 3 a 11 del informe el régimen foral tradicional navarro, conceptualizado como "la constitución política de Navarra", entre las páginas 11 a 17 se explica "cómo podría lograrse su restauración". Se consideraba que "el restablecimiento íntegro y total de aquel régimen sería hoy punto menos que imposible, dada la comunidad de relaciones e intereses que el progreso moderno ha establecido entre las distintas regiones españolas y dado también el concepto y las necesidades del Estado moderno", así como que aspectos como "la exención de quintas, la existencia de las Aduanas, la facultad de batir moneda etc." no podian "mantenerse hoy sin quebrantar las prerrogativas inherentes a la soberanía del Estado". Por otra parte, "la multiplicidad de relaciones e intereses creados entre las distintas regiones de España por el progreso de los tiempos, la difusión de la riqueza y el enorme adelanto de las comunicaciones exige hoy la adopción de normas nuevas y distintas que regulen la vida de relación con el Estado, aunque dentro de ellas se quiera mantener, en lo que sea posible y conveniente, el espíritu de libertad que animaba la constitución política de Navarra en aquella época".

En lo que se refería "al régimen interior" de Navarra, "las antiguas instituciones forales" debían "de ser también profundamente transformadas para adaptarlas a las necesidades de la vida actual", ahondándose en "cómo y por quién habría de llevarse a cabo" dicha labor.

Para Oroz había "que descartar desde luego el procedimiento de dictar una Ley o disposición análoga por la cual se quiera reconocer a Navarra determinadas facultades autonómicas, por muy amplias que sean, pues ello significaría la infracción de uno de los principios más esenciales del Fuero en cuanto que dispone que las leyes, las disposiciones generales a manera de Ley y las Ordenanzas decisivas, no se hagan sino a pedimento $y$ otorgamento de los tres Estados y estaríamos en el caso de los Estatutos autorizados por la Constitución republicana, que por esta, precisamente, entre otras razones, fueron tan enérgicamente rechazados por los Ayuntamientos navarros". Se apuntaba que "el camino a seguir dentro del cauce foral es que, previa una disposición del Poder público en que se declarase restablecido en toda su integridad el régimen foral que Navarra disfrutaba antes de la reforma constitucional del año 1812, derogando las leyes abolitorias del mismo dictadas con posterioridad, se dieran las normas oportunas para constituir una Asamblea representativa de Navarra, que investida de las facultades que tenian las antiguas Cortes, aprobara y propusiera a la sanción del Soberano o Jefe Superior de la Nación, en forma de ley, las bases fundamentales de la Constitución política interior de Navarra y de sus relaciones con el Estado". Dicha Asamblea "designaría de su seno a la Diputación, como órgano ejecutivo, para la Administración y Gobierno de Navarra, y ambos organismos en representación del País, partiendo del régimen actual, irian preparando la labor legislativa necesaria para restablecer y poner en práctica las demás instituciones forales, de acuerdo con las necesidades de los 
tiempos presentes y de los principios fundamentales imperantes en a obra del nuevo Estado".

En cuanto a los componentes de esa Asamblea, se asumía la imposibilidad de contar con "las mismas representaciones de que se componian nuestras antiguas Cortes" ya que en el caso de "los Brazos Eclesiástico y Noble" "la mayor parte de sus componentes ya no existen y aunque existieran no podrian considerarse hoy como representación auténtica del País". Para Oroz, "podria, en cambio, tomarse como base el actual Consejo Foral Administrativo de Navarra, compuesto con mayoría de representanets de los Ayuntamientos, y completada con otras representaciones de las fuerzas vivas del País, como son las de Agricultura, Ganadería, Industria y Comercio, Propiedad Urbana, Profesiones intelectuales y clase obrera, o valerse de otras representaciones análogas, sacadas de la organización Corporativa o Sindical del nuevo Estado". "A estas representaciones podian agregarse otras de la Iglesia y el Ejército, en recuerdo de los antiguos Brazos o Estamentos y que hoy no pueden faltar dadas las orientaciones plausiblemente iniciadas por el Glorioso Alzamiento nacional, así como tampoco podría prescindirse de la FET y de las JONS que ostenta la dirección política del Movimiento". Por último, "la misma Asamblea, al constituirse, debería designar dos Síndicos-Asesores, como los que tenian las Cortes, que hoy, dada la enorme labor legislativa que estas tendrian que desarrollar, serian imprescindibles".

Por lo tanto, como se puede ver, incluso en la primavera de 1939, había sectores del tradicionalismo que seguían interesados en cómo debería implementarse la Reintegración Foral, asumiendo la dificultad del empeño. Aún cuando no se hiciera mención alguna a su compatibilidad con el nuevo Estado franquista, este ya estaba dando muestras de que su respeto por la foralidad navarra no iría más allá de lo que definía el marco cuarentayunista, algo ya asumido por la propia Gestora de la Diputación. Recordemos que a lo largo de los años de la guerra civil surgieron repetidos conflictos entre la Diputación navarra $\mathrm{y}$ las autoridades del bando franquista por diversas cuestiones, teniendo que ceder aquella en el tema del subsidio familiar a obreros y empleados y en el del nombramiento de inspectores de educación ${ }^{70}$. Pocos años después, el apoyo activo de la mayoría de la población navarra hacia el bando nacional y el discurso foralista de la derecha navarra en el que se compatibilizaban la defensa de las especificidades navarras dentro del marco de la ley de 1841 con la de la indisoluble unidad de España en un discurso en el que Navarra aparecía como el bastión último de las esencias patrias, del catolicismo y del anticomunismo no impidieron las tenatativas uniformizadoras de gobernadores civiles falangistas como Juan Jonquera y Luis Valera Bermejo que entre 1945 y 1954 desataron diversos conflictos con la Diputación y con diversas instituciones navarras. E1 primero tuvo que afrontar la dimisión en pleno del ayuntamiento de Pamplona en julio de 1946 por el cierre del Círculo Carlista a consecuencia de los enfrentamientos entre tradicionalistas y falangistas en la Plaza del Castillo en diciembre de 1945, e intentó prohibir en 1948 la inserción en el Boletín Oficial Provincial de las disposiciones de la Diputación no autorizadas por el Gobierno Civil. El segundo se esforzó por controlar los ayuntamientos, en especial el de

70 Ángel Pascual Bonis, "La actividad de las gestoras de la Diputación Foral (1931-1939) y sus relaciones con el poder central”, op. cit., pp. 483-485. 
Pamplona, maniobrando para extender la influencia del Movimiento a través de las oportunidades que le ofrecía la división del carlismo; presionó para incorporar a miembros de FET y de las JONS en la Junta de Educación; disputó con la Corporación foral en relación con las competencias de ésta sobre los ayuntamientos; llegó a deponer a los diputados que se le oponían de sus cargos gubernativos o en el Movimiento, acusándoles de secesionismo; y se enfrentó duramente con el ayuntamiento pamplonés. En los dos casos las gestiones de la Diputación ante Franco se saldaron con el cese del gobernador. Precisamente, esa actitud de defensa de la foralidad por parte de la Diputación frente a los intentos centralizadores del Movimiento tuvo como efecto el surgimiento del navarrismo foralcatólico como objeto de elaboración teórica, sobre todo desde el derecho y de la historia ${ }^{71}$ por medio de la profundización en las tesis postuladas por Eladio Esparza desde finales de los años veinte.

Enviado el (Submission Date): 31/03/2021

Aceptado el (Acceptance Date): 23/04/2021

71 Álvaro Baraibar Etxeberria, "Contrafueros, <<secesionismo navarro>> o control provincial: la pugna entre los Gobernadores Civiles y la Diputación (1945-1955)", en Maria del Mar Larraza Micheltorena (Dir.), De leal a disidente: Pamplona, 1936-1977, Pamplona, Ediciones Eunate, 2006, pp. 89-114. 